


\begin{abstract}
Six different convective-stratiform separation techniques, including a new technique that utilizes the ratio of vertical and terminal velocities, are compared and evaluated using two-dimensional numerical simulations of a tropical [Tropical Ocean Global Atmosphere Coupled OceanAtmosphere Response Experiment (TOGA COARE)] and midlatitude continental [Preliminary Regional Experiment for STORM-Central (PRESTORM)] squall line. Comparisons are made in terms of rainfall, cloud coverage, mass fluxes, apparent heating and moistening, mean hydrometeor profiles, CFADs (Contoured Frequency with Altitude Diagrams), microphysics, and latent heating retrieval. Overall, it was found that the different separation techniques produced results that qualitatively agreed. However, the quantitative differences were significant. Observational comparisons were unable to conclusively evaluate the performance of the techniques. Latent heating retrieval was shown to be sensative to the use of separation technique mainly due to the stratiform region for methods that found very little stratiform rain.
\end{abstract}




\title{
Modeling of Convective-Stratiform Precipitation Processes: Sensitivity to Partitioning Methods
}

\author{
S. E. Lang, W.-K. Tao, J. Simpson, and B. Ferrier \\ Submitted to: Journal of Applied Meteorology
}

\section{POPULAR SUMMARY}

Convective cloud systems such as squall lines consist of two rather distinct regions: the convective region contains clouds with strong vertical motion and heavy rainfall similar to thunderstorms and the stratiform region which is usually a broader area of clouds with weak vertical motion and light rainfall. Cloud systems are composed of tiny cloud droplets and ice crystals as well as larger rain drops and ice. These cloud particles interact differently in the two regions. Their interaction leads to the release of heat due to phase changes of water. As such, the separation of convective systems into their two regions reveals the vertical location and amount of heating that takes place in each region (which is characteristically different) as well as the amount of rainfall in each region. Several different techniques have been developed to perform such separation. They rely on different criteria such as the strength of vertical motion, rainfall rates or the intensity of radar echoes to name the most common. Typically the convective region is identified with the remainder assumed to be stratiform. Results from six different separation techniques agreed well with each other qualitatively but differed significantly quantitatively.

Comparisons with observed statistics were insufficient to identify the method that performed the best separation. However, stratiform heating profiles in situations where techniques assign most of the rainfall in a convective cloud system to the convective region lead to errors when those profiles are used in connection with other measured quantities to estimate the total heating profiles for such systems. Heating profiles ultimately can be used to initialize large-scale weather models. 


\section{Introduction}

Squall lines are part of an important class of precipitating convective systems, often referred to as mesoscale convective systems or MCSs. They can produce abundant rainfall, severe weather, and impact the large-scale environment. Squall lines or MCSs can be separated into two regions: convective and stratiform. There are several reasons for making this distinction. First, the precipitation mechanisms are decidedly different in the two regions. Also, the convective region generally contains the heavier precipitation rates. In addition, the vertical profiles of latent heating are distinctly different, each having its own characteristic shape. The same is true for the mass flux and divergence profiles. As such, a number of techniques have been developed to separate convective systems into their convective and stratiform components. The purpose of this study is to compare several of those techniques using a numerical cloud-resolving model and assess the impact of their usage.

An early study by Hamilton and Archbold (1945) described a typical squall line as a line of cumulonimbus clouds that preceded a broad downdraft region associated with a precipitating anvil. Newton (1950) discovered a subsidence inversion behind a squall line, and Zipser (1977) put forth a conceptual model wherein the downdraft area consisted of narrow convective-scale and an evaporatively driven broader mesoscale downdraft that originated from mid-level inflow. This formed a stable layer behind the leading edge convection. Brown (1979) modeled such a mesoscale downdraft using a two-dimensional (2D) hydrostatic model. The stratiform precipitation in the anvil is often associated with a distinct radar bright band (Ryde 1946; Battan 1973; Atlas 1990). The horizontally uniform precipitation of the anvil region has been found to contain rainfall rates on the order of 1 to $10 \mathrm{~mm} / \mathrm{h}$ compared to 10 to $100 \mathrm{~mm} / \mathrm{h}$ in the convective cores (Leary and Houze 1979). The convective region is usually dominated by rimed particles or graupel as opposed to aggregates in the anvil region (Churchill and Houze 1984). 
Using radar data Houze (1977) computed the anvil portion of the rainfall for a GATE squall line to be about $40 \%$. He simply drew a boundary around the squall line region (i.e., the convective portion) and treated the rest as anvil. Gamache and Houze (1982) obtained quantitative divergence and mass flux profiles for both the convective and anvil regions of a GATE squall line. They separated the convective and anvil portions based on subjective assessment of the echo pattern. They found the squall-line echo to have an average width of 20 $\mathrm{km}$.

An important aspect of squall lines involves their influence on the larger scale, notably in the form of heating and moistening. Reed and Recker (1971) obtained an estimate of the diabatic heating effects above $900 \mathrm{mb}$ for a composite easterly wave disturbance. Yanai et al. (1973) used a similar approach to estimate the apparent heating and moistening for tropical disturbances also observed in the Marshall Islands. Their time-averaged heating profile matched that of Recker and Reed (1971) fairly well with a single maximum in heating near 475 $\mathrm{mb}$. These early estimates represented the heating effects for an entire convective system.

Leary and Houze (1979) used GATE radar data to estimate cooling rates in and below the anvil bright band due to melting and evaporation. But, Houze (1982) used an idealized cloud system to put forth the first comprehensive estimates of the heating profiles associated with the convective and anvil regions by summing estimates of the cloud-scale terms. The convective profiles showed warming throughout the depth of the troposphere while the anvil profiles had warming in the middle and upper troposphere and cooling due to evaporation and melting in the lower troposphere. Johnson and Young (1983) computed the heating and moistening rates for tropical anvils using soundings from a ship array. Their results compared well with those of Houze (1982). Johnson (1984) partitioned the apparent heat and moisture source profiles of Yanai et al. (1973) using the anvil profiles of Johnson and Young (1983). 
The cumulus profiles were obtained as the residual and generally matched that of Houze (1982).

Tao and Soong (1986) used a three-dimensional (3D) numerical cloud model to simulate a GATE rainband. They produced total heating and moistening profiles similar to those from observational studies. Tao and Simpson (1989) added ice microphysics and a convective-stratiform separation technique based on Churchill and Houze (1984) to produce model simulated profiles of heating for the convective and anvil regions. These convective and anvil heating profiles were similar to those obtained by Houze (1982) and Johnson (1984).

Recent studies (Simpson et al. 1988; Adler and Negri 1988; Tao et al. 1993a) have shown that the separation of convective and stratiform clouds is necessary for the successful retrieval of surface rain and latent heating profiles via remote sensing. Frank and McBride (1989) concluded that differences in the total heating profiles between AMEX and GATE cloud clusters were due to differences in the fraction of anvil rainfall. Using similar logic, Tao et al. (1993a) put forth an algorithm to retrieve the mean latent heating profile based on rainfall, the stratiform percentage, and appropriate profiles of heating characteristic of the convective and stratiform regions. The convective and stratiform heating profiles used in the algorithm are obtained from both diagnostic and modeling studies of convective systems from various geographic regions. They indicated that the stratiform percentage should be within $10 \%$ for an accurate retrieval. Alexander and Cotton (1998) recently devised a mesoscale parameterization scheme to accompany a modified traditional cumulus parameterization scheme. They used the Tao et al. (1993b) separation technique to select mesoscale profiles for their parameterization from cloud resolving model simulations of MCSs.

Recent cloud modeling studies (e.g., Tao et al. 1993b; Xu 1995; Caniaux et al. 1994) have quantified the amount of stratiform rain, and the heating and moisture budgets of MCSs 
using different separation techniques. Current convective-stratiform separation for TRMM ground validation radars follows the algorithm of Steiner et al. (1995). Though the exact demarcation between the convective and stratiform regions can be arbitrary, such separation has many uses. As such, it is important to compare the various separation methods in use to determine whether similar conclusions are obtained and to assess the variance of any quantitative differences. This paper will address the issue by comparing five different separation

techniques currently being used plus a new method based on the definition that the terminal velocity of precipitation particles is large relative to the vertical velocity in regions of stratiform precipitation (e.g., Houghton 1968; Steiner el al. 1995; Houze 1997). These techniques are applied to two different squall line cases: a mid-latitude case (PRESTORM) and a tropical case (TOGA COARE). The model and cases are described in Section 2. Section 3 gives the details on the convective-stratiform separation methods, and Section 4 contains the results of the numerical experiments. The summary and conclusions are given in Section 5.

\section{Model Description and Case Studies}

The model used in this study is the 2D version of the Goddard Cumulus Ensemble (GCE) model. Modeled flow is anelastic. The microphysics include a parameterized Kessler-type two-category liquid water scheme (cloud water and rain), and parameterized Lin et al. (1983) or Rutledge and Hobbs (1984) three-category ice-phase scheme (cloud ice, snow and hail/graupel). Second- or higher-order advection schemes can produce negative values in the solution (Soong and Ogura 1973). Thus, a Multi-dimensional Positive Definite Advection Transport Algorithm (MPDATA - Smolarkiewicz 1983; Smolarkiewicz 1984; Smolarkiewicz and Grabowski 1990) has been implemented into the model. All scalar variables (potential temperature, water vapor, turbulent coefficient and all five hydrometeor classes) use forward time differencing and the MPDATA for advection. Dynamic variables, $u, v$ and $w$, use a 
second-order accurate advection scheme and a leapfrog time integration (kinetic energy semiconserving method). Short-wave (solar) and long-wave radiation parameterizations as well as a subgrid-scale turbulence (one-and-a-half order) scheme are also included in the model. Details of the model can be found in Tao and Simpson (1993) and Simpson and Tao (1993).

Two cases, a tropical oceanic squall system observed during TOGA COARE (Tropical Ocean Global Atmosphere Coupled Ocean-Atmosphere Response Experiment) and a midlatitude continental squall system observed during PRESTORM (Preliminary Regional Experiment for STORM-Central), will be used to examine the various partitioning methods. The June 10-11, 1985 PRESTORM case is well studied (e.g., Johnson and Hamilton 1988; Rutledge et al. 1988; Tao et al. 1993b; Tao et al. 1996). The PRESTORM environment was fairly unstable but relatively dry. The model was initialized with a single sounding taken at 2330 UTC from Pratt, KS which was ahead of the newly forming squall line. The sounding is quite unstable with a lifted index of -5.37 and a Convective Available Potential Energy (CAPE) of $2300 \mathrm{~J} / \mathrm{kg}$. The PRESTORM simulations were made using a modified shear profile [see Tao et al. (1993b)] and Lin et al. (1983) microphysics. A stretched vertical coordinate was used in the model with 31 grid points. The resolution ranged from $240 \mathrm{~m}$ at the lowest level to 1250 $\mathrm{m}$ at the top. There were 1024 horizontal grid points; the central 872 had a fixed $1 \mathrm{~km}$ resolution. The outer grids were stretched. Radiation was included but not surface fluxes. The time step was 6 seconds. The convective system was initiated using a low-level cold pool.

The February 22, 1993 TOGA COARE squall line has also been well studied (Jorgensen et al. 1997; Redelsperger et al. 2000; Trier et al. 1996, 1997; Wang et al. 1996, 2001). The sounding used to initialize the model is from LeMone et al. (1994). It is a composite of aircraft data below $6 \mathrm{~km}$ and an average of the 1800 and 2400 UTC Honiara soundings above $6 \mathrm{~km}$. The surface values follow Redelsperger et al. (2000). The CAPE and lifted index are moderately unstable, $1776 \mathrm{~J} / \mathrm{kg}$ and -3.2 , respectively. A low-level westerly jet 
of $12 \mathrm{~m} / \mathrm{s}$ is present near $2 \mathrm{~km}$. The observed squall line propagated eastward perpendicular to the jet. Though initially linear, the system later evolved into a bow with a mid-level vortex on the northern edge. Surface fluxes were included in the model for this case using the TOGA COARE flux algorithm (Fairall et al. 1996; Wang et al. 1996). The vertical grid was similar to the PRESTORM setup, but with the first grid level at $40 \mathrm{~m}$ to accomodate the TOGA COARE flux algorithm. A time step of 5 seconds was required. The horizontal grid followed that for PRESTORM, but with an inner resolution of $750 \mathrm{~m}$. A modified version of the Rutledge and Hobbs (1984) 3-class ice scheme was used, and the shear above the low-level jet was reduced. Radiation was included, and a low-level cold pool was used to start the system. Low-level mesoscale lifting was also applied. It had a peak value of $3.4 \mathrm{~cm} / \mathrm{s}$ near $1 \mathrm{~km}$ and was applied over the first 2 hours. Table 1 shows some characteristics of the environments.

\subsection{Convection-Stratiform Partitioning}

\subsection{Churchill and Houze (1984)}

Based on work by Houze (1973), the Churchill and Houze (1984) method identifies convective cores as having twice the rainfall rate of the background average. The points surrounding the core point are also convective as is any point with a rainrate above $20 \mathrm{~mm} / \mathrm{h}$. The background average is from a box 5 grid points on a side. Originally applied to gridded radar data with a 4 $\mathrm{km}$ horizontal spacing at a $3 \mathrm{~km}$ altitude, in the model, it is applied to surface rainfall and on a finer grid. Also, the $20 \mathrm{~mm} / \mathrm{h}$ convective threshold is allowed to vary between 10 and $25 \mathrm{~mm} / \mathrm{h}$ depending on the time of the simulation. This method is termed the " $\mathrm{C} \& \mathrm{H}$ method" hereafter.

\subsection{Tao and Simpson (1989) and Tao et al. (1993b)}

This method begins with the $\mathrm{C} \& \mathrm{H}$ method applied to surface rainfall. Two additional criteria 
are then applied to identify active convection aloft having minimal surface rainfall, such as tilted updrafts and new cells ahead of the line (Tao et al. 1993b). A point is made convective if cloud water exceeds a threshold (i.e., $0.5 \mathrm{~g} \mathrm{~kg}-1$ or half the current maximum cloud water content), or if the updraft exceeds $3 \mathrm{~m} \mathrm{~s}-1$ below the melting level. In the stratiform area, updraft velocity is checked above the melting level. If it exceeds $5 \mathrm{~m} / \mathrm{s}$ or half the current maximum updraft, the area is made convective. Also, if the combined cloud water and cloud ice content above the melting level exceeds $1.5 \mathrm{~g} / \mathrm{kg}$ or half their current maximum combined content, the point is made convective. The thresholds are adjusted for different cloud systems as well as for the stage in their life cycle. Cloud areas ahead of the gust front are also made convective to achieve coherent areas of convective and stratiform rainfall. This method is termed the "GCE method" and has been adopted by Chin (1994) and Alexander and Cotton (1998).

\section{$3.3 \quad$ Хu(1995)}

This method is similar to the C\&H method only vertical motion instead of rainfall is used. Below the melting level, model columns with an absolute vertical velocity twice the background average over the four surrounding grid points are convective cores. The points on either side of the core are also convective. Also, any point with a rainrate over $25 \mathrm{~mm} / \mathrm{h}$ or an absolute vertical velocity over $3 \mathrm{~m} / \mathrm{s}$ is made convective. Remaining columns with a liquid water path over 0.2 $\mathrm{kg} / \mathrm{m} 2$ are stratiform. These are checked for shallow convection. Columns with cloud water paths over $0.4 \mathrm{~kg} / \mathrm{m} 2$, rain water paths below $0.1 \mathrm{~kg} / \mathrm{m} 2$ and mean upward motion all below the melting layer are made convective. However, for this study, the stratiform region is simply the non-convective rainy area. Also, the rainrate threshold was not fixed at $25 \mathrm{~mm} / \mathrm{h}$ but varied between 10 and $25 \mathrm{~mm} / \mathrm{h}$, and the velocity threshold was the minimum between $3 \mathrm{~m} / \mathrm{s}$ and a fourth of the current maximum vertical velocity. This method is termed the "Xu method".

\subsection{Caniaux et al. (1994)}


In this method, a characteristic width or fixed number of model grid points (e.g., 20-40) are centered on the maximum surface rainrate and designated as the convective region. Remaining grid points with surface precipitation comprise the stratiform region. In this study, the convective region was fixed at a width of $20 \mathrm{~km}$, so it is referred to as the "CA20 method".

\subsection{Steiner et al. (1995)}

This method is a texture algorithm applied to radar data below the melting band and builds on the earlier $\mathrm{C} \& \mathrm{H}$ method. Reflectivities are compared against a background average taken over a $11-\mathrm{km}$ radius. Points exceeding the average by a certain threshold are convective. The threshold varies as a function of the background average. Also, any point that exceeds $40 \mathrm{dBZ}$ is convective. For each of the points identified as convective, a surrounding area that depends upon the intensity of the core point is made convective. The remaining rainy areas are then stratiform.

\subsection{Vt-W Method}

A new method is introduced based on the premise that the fall speed of precipitation particles is large relative to the vertical velocity in regions of stratiform precipitation (e.g., Houghton 1968; Steiner el al. 1995; Houze 1997). In this method, if the ratio of fall velocity to vertical velocity exceeds the square root of an order of magnitude (i.e., 3.16), the point is considered stratiform. Only regions of the cloud volume where the fall velocity and vertical velocity exceed 2 and $1 \mathrm{~m} / \mathrm{s}$, respectively, are examined. Above the melting layer, only positive values of $\mathrm{W}$ are used in the ratio. Finally, below the melting layer, new convection is identified by any point that has vertical velocity and cloud water over $1 \mathrm{~m} / \mathrm{s}$ and $0.1 \mathrm{~g} / \mathrm{kg}$, repsectively. 
In this study, two criteria adopted in the GCE method are applied to all the others. First, surface rainrates are thresholded. The threshold varies from 10 to $25 \mathrm{~mm} / \mathrm{h}$ depending on the simulation time and the value of the current maximum surface rainrate. Points that exceed the threshold are always convective. Second, an attempt is made to make the convective and stratiform regions coherent. First stratiform or cloudy points ahead of the gust front are made convective. Next, cloudy points in the stratiform area behind the convective area are made stratiform. Finally, if the convective region is 5 points or less in width, any stratiform points in between are made convective. Table 2 lists characteristics of the various methods.

\section{Results and Discussion}

Simulations were made for 720 minutes for both PRESTORM and TOGA COARE. Figure 1 shows vertical cross-sections of estimated radar reflectivity for both runs. Both show a classic squall-line structure (e.g., Gamache and Houze 1982) with a leading convective edge and trailing stratiform region. In PRESTORM, echo cores exceed $50 \mathrm{dBZ}$ and regularly reach 60 $\mathrm{dBZ}$. The $50 \mathrm{dBZ}$ values can reach upwards of $6 \mathrm{~km}$. In TOGA COARE, core values exceed $50 \mathrm{dBZ}$ but not $60 \mathrm{dBZ}$. The $50 \mathrm{dBZ}$ echoes in TOGA COARE occur below $3 \mathrm{~km}$. The results agree favorably with observed Doppler derived reflectivity and vertical velocity structures (Jorgensen et al. 1997). Compared to PRESTORM, the transition from convective to stratiform is less obvious due to the persistence of cellular structures behind the leading edge. The leading convective cells in the PRESTORM case penetrate well above freezing where hydrometeors are more likely to be carried rearward to form a more discerable bright band.

Hovmoller diagrams of surface rainfall, are presented in Figure 2 for both cases. Both show a surge in forward propagation speed as the systems mature. The surge accompanies a broadening of the stratiform region and likely indicates the transition from an erect to an 
upshear updraft profile (Ferrier et al. 1996).

\subsection{Rainfall Statistics}

Figure 3 a shows time series of instantaneous grid-averaged total and stratiform rainfall for the PRESTORM case using the GCE separation method. The stratiform amount slowly increases over the simulation. The total rainfall levels off after 240 minuntes. A distinct episode of increased rainfall just after 480 minutes can be traced to the merger of new cell ahead of the main line with the system. This merging can lead to enhanced rainfall (Byers and Braham 1949; Simpson 1980; Wescott 1984; Tao and Simpson 1984, 1989). Figure 3b shows the results the TOGA COARE case. Stratiform rain increases more rapidly than in PRESTORM before leveling off.

Results from the various separation techniques are shown in Table 3 . The variability is rather high. In PRESTORM, C\&H has the most stratiform rain followed closely by GCE and CA20. Xu detects a modest amount, while Vt-W and Steiner have very low amounts. The spread is $18 \%$. Johnson and Hamilton (1988) reported an average stratiform rain amount of $29 \%$ for this case using surface rain gauge data. As the system matures, the stratiform percentage increases both for the model results and observations. If the stratiform percentage is computed over the final 240 minutes of the simulation, in the mature stage, the GCE, C\&H, Xu, and CA20 estimates increase by $10 \%$ and Steiner and Vt-W increase by $2-5 \%$. Johnson and Hamilton (1988) estimated the observed mature stage stratiform portion to be between 30 and $40 \%$. Thus all of the stratiform estimates appear too low though GCE, C\&H and CA20 are reasonably close especially for the mature stage. Johnson and Hamilton (1988) assigned rainrates over $6 \mathrm{~mm} / \mathrm{h}$ as convective in their analysis of the mesonet rain gauge data. Using this same criterion to the model results in a stratiform rain percentage of just $4.2 \%$, which is now very close to the Steiner and Vt-W estimates. Obviously the rainfall distribution in the model 
does not match the observations and appears biased towards heavy rainrates. Sui et al. (1998) also found this bias with the model.

In TOGA COARE, $\mathrm{C} \& \mathrm{H}, \mathrm{GCE}$, and $\mathrm{Xu}$ have the most stratiform rain. CA20 is now less than $\mathrm{Xu}$, and $\mathrm{Vt}-\mathrm{W}$ and Steiner still give the lowest stratiform totals. The range is now $32 \%$. Short et al. (1997) reported that $40 \%$ of the rainfall that occurred during active periods in TOGA COARE was stratiform. Active periods were mostly associated with organized convection. They used a texture algorithm similar to $\mathrm{C} \& \mathrm{H}$ and Steiner to separate rain maps derived from shipboard radar data into convective and stratiform. Thus, the GCE, C\&H, and Xu methods appear favorably close. However, the same issue of how well the model replicates the observed rainfall distribution remains. The comparison with observed values are thus rather inconclusive.

In both cases, the Steiner method has the lowest stratiform amount. The method was designed for a 2-km grid, whereas the model resolution is $1 \mathrm{~km}$ in PRESTORM and $0.75 \mathrm{~km}$ in TOGA COARE. If applied on a finer grid than the original $2 \mathrm{~km}$, it will detect small scale deviations and identify them as convective and overestimate the convective amount (Steiner et al. 1995). Nevertheless in its current usage, for PRESTORM, regions that it finds convective are always close to echoes of $40 \mathrm{dBZ}$ (Fig. 1), and in TOGA COARE it identifies the same cellular structures as the Vt-W method. So, based on the simulated reflectivity structures and the possible bias towards high rainrates in the model, it appears to perform reasonably.

\subsection{Area Cloud Coverage}

Vertical profiles of cloud coverage are shown in Fig. 4 for each case. Grid points that had total hydrometeor contents in excess of $0.01 \mathrm{~g} / \mathrm{m} 3$ were considered cloudy. The PRESTORM case shows a broad area aloft near $11 \mathrm{~km}$ that is associated with the non-surface-precipitating portion 
of the anvil. The mean width of the cloudy area is $304 \mathrm{~km}$. In the TOGA COARE case, the average cloud area is $161 \mathrm{~km}$ with no discernable maximum aloft.

The PRESTORM stratiform area slowly but steadily increased with time eventually flattening out over the final 2 hours of the simulation time. The average width of the stratiform region over the entire 12-hour simulation time for all 6 methods was $43 \mathrm{~km}$ (Table 4). The mean width ranged from $50 \mathrm{~km}$ for $\mathrm{C} \& \mathrm{H}$ to $29 \mathrm{~km}$ for $\mathrm{Vt}-\mathrm{W}$. The mean convective width for the entire simulation was $95 \mathrm{~km}$ and varied from $87 \mathrm{~km}$ for $\mathrm{C} \& \mathrm{H}$ to $110 \mathrm{~km}$ for $\mathrm{Vt}-\mathrm{W}$. Because of the coherence approach, the CA20 method had an average convective width of $91 \mathrm{~km}$ due to the forward anvil. This agrees quite well with the ensemble average.

In TOGA COARE, the stratiform area also shows a slow, steady increase over the simulation. The resulting mean 12-hour stratiform width (Table 4) was $56 \mathrm{~km}$ and varied from $43 \mathrm{~km}$ for $\mathrm{Vt}-\mathrm{W}$ up to $67 \mathrm{~km}$ for $\mathrm{C} \& \mathrm{H}$. The mean convective width of $27 \mathrm{~km}$ was much smaller than in PRESTORM partially due to the forward anvil in the PRESTORM case. The characteristic $20 \mathrm{~km}$ convective width assumed in the CA20 approach yields a 12-hour average of $28 \mathrm{~km}$ which again agrees quite well with the ensemble average.

\subsection{Cloud Mass Fluxes}

Accumulated mass fluxes for the PRESTORM case are shown in Fig. 5. The fluxes are subdivided into convective and anvil using the GCE method. The convective profile has ascent at all levels with a single maximum at $4 \mathrm{~km}$. The anvil has a single upward peak at $9 \mathrm{~km}$ and a single downward peak at $3 \mathrm{~km}$. The TOGA COARE fluxes are shown in Fig. 5. The results are generally similar to PRESTORM. The convective peak is sharper and lower at $2.5 \mathrm{~km}$. The anvil profile has maximum ascent at $9 \mathrm{~km}$ and maximum descent at $2.5 \mathrm{~km}$. 
Figure 6a shows accumulated mass flux profiles separated into convective and anvil for PRESTORM for each of the six separation techniques. Qualitatively, they are similar. Convective profiles all show net ascent throughout the troposphere with a single maximum. The anvil profiles all show net ascent aloft and net descent in the lower troposphere. The height of the convective peak varies between 3.5 and $6 \mathrm{~km}$. It's magnitude varies between 110 and 130 $\mathrm{g} / \mathrm{cm} 2 /$ grid. The anvil peaks vary between 8 and $10 \mathrm{~km}$ in height but differ by up to 50 $\mathrm{g} / \mathrm{cm} 2 /$ grid in magnitude. In general, the results mimic those for rainfall with having $\mathrm{C} \& \mathrm{H}$ the largest anvil peak and $\mathrm{Vt}-\mathrm{W}$ the smallest. CA20 differs from the rest at low levels. There are two main downdrafts behind the leading edge updraft. The first is about $5-10 \mathrm{~km}$ to the rear of the leading edge and the second $20-25 \mathrm{~km}$ back. All of the methods include the first downdraft in the convective region. The fixed convective area of the CA20 method does not encompass the second downdraft while the other methods occasionally mark it convective.

Compared to PRESTORM, TOGA COARE profiles (Fig. 6b) are less variable at low levels but more variable aloft. Almost all of the methods place the peak convective flux at 2.5 $\mathrm{km}$. The magnitudes vary from 40 to $65 \mathrm{~g} / \mathrm{cm} 2 / \mathrm{grid}$. The low-level downward peaks in the anvil are all at $2.5 \mathrm{~km}$. The real variation is above the freezing level. C\&H, GCE and CA20 have nearly identical results with dominant anvil profiles while $\mathrm{Xu}$, Steiner, and $\mathrm{Vt}-\mathrm{W}$ increasingly categorize upward mass fluxes above the melting level as convective. The differences are due to updrafts associated with cells behind the leading edge. Occassionally Xu treated parts of these cells as convective. Steiner and especially Vt-W were even more likely to call them convective. Frequently these cells contained updrafts aloft on the order of 1 to $2 \mathrm{~m} / \mathrm{s}$. The differences are enough for the $\mathrm{Vt}-\mathrm{W}$ profile to have a different in shape.

\subsection{Apparent Heating (Q1) and Moistening (Q2)}

Q1 profiles for PRESTORM are shown in Fig. 7a. Total Q1 has a maximum at $7 \mathrm{~km}$ and a 
secondary peak near $13 \mathrm{~km}$. Heating prevails in the troposphere while cooling occurs above the tropopause. Separation is according to the GCE method. The convective profile shows heating throughout with a peak at $5.5 \mathrm{~km}$. The anvil profile has cooling below $5 \mathrm{~km}$, though the freezing level is near $4 \mathrm{~km}$, and heating aloft with a maximum at $9 \mathrm{~km}$ and another nearly as large near $14 \mathrm{~km}$. All of the profiles have been normalized by the total surface rainfall. Convective and anvil profiles are split into components in Fig. 8a\&b. Condensation and deposition dominate the convective area. The other terms are small but significant. Deposition and sublimation are the dominant terms in the anvil. The eddy flux term is responsible for the secondary heating peak aloft and for the cooling above the tropopause.

The TOGA COARE Q1 profiles are shown in Fig. 7b. Total Q1 again peaks at $7 \mathrm{~km}$ though the peak is flatter than in PRESTORM. Convective heating peaks at $2.5 \mathrm{~km}$ while in the anvil, low-level cooling and upper-level heating are stronger. Weaker updrafts lead to less heating and cooling near the tropopause than in PRESTORM. The component profiles are shown in Figs. $8 c \&$ d. Condensation totally dominates the convective region such that the other terms are minor. Heating is almost evenly divided between condensation and deposition in the anvil, but evaporation is quite large below $5 \mathrm{~km}$.

Normalized Q1 profiles for each of the separation techniques are shown in Fig. 9a for PRESTORM. The overall shapes are quite similar with the only real differences being in the magnitudes at midlevels. Steiner and $\mathrm{Vt}-\mathrm{W}$ have the most convective heating. $\mathrm{C} \& \mathrm{H}$ has the most anvil heating. The biggest variance is at $7 \mathrm{~km}$ where heating rates vary by $0.33 \mathrm{deg} / \mathrm{mm}$. Below the melting level and above $9 \mathrm{~km}$, differences are quite small, on the order of 0.1 $\mathrm{deg} / \mathrm{mm}$.

Results for TOGA COARE are shown in Fig. 9b. The techniques again show close agreement below the melting level. This uniformity occurs eventhough the convective areas may 
differ significantly and can be attributed to the lack of any strong heating or cooling beyond the vicinity of the leading edge. Steiner and $\mathrm{Vt}-\mathrm{W}$, which on average have much larger convective regions, yield only slightly less anvil cooling compared to the others. In PRESTORM, strong pockets of cooling, due to evaporation or even melting, can exist further behind the leading edge below the melting level, the moist environment of the tropics mitigates this effect. The results are different aloft. GCE, CA20 and C\&H all produce similar profiles above the freezing level with nearly all the heating assigned to the anvil region. Xu assigns slightly more of the heating aloft to the convective region. Steiner has even more convective heating aloft while Vt-W has the most, noticeably more than even Steiner. The variation is due to the decaying cells behind the leading edge. Unlike below the melting level, they can contain areas of significant heating aloft.

Q2 profiles for PRESTORM and TOGA COARE are shown in Fig. 10. The TOGA COARE anvil profile shows moistening below $4.5 \mathrm{~km}$, similar to PRESTORM only stronger. Both convective profiles show drying mainly below $5 \mathrm{~km}$. The TOGA COARE profile peaks at $3.5 \mathrm{~km}$ and the PRESTORM profile at $2.5 \mathrm{~km}$.

Q2 profiles separated into convective and stratiform are shown in Fig. 11. The PRESTORM profiles have more variation at low levels, due mainly to CA20, while the TOGA COARE profiles have more variation at upper levels. The shapes are similar in each case except in TOGA COARE where Steiner and Vt-W are different aloft.

\subsection{Hydrometeor Profiles}

Total hydrometeor profiles for both cases are shown in Fig. 12. GCE is the only method that directly utilizes hydrometeor data to differentiate between convective and stratiform. Large values of cloud water or cloud ice are associated with significant updrafts that are a sign of convection. Hydrometeor contents were computed for the convective and stratiform regions for 
each of the separation techniques. In PRESTORM, most cloud water is found to be convective ranging from over $97 \%$ for Steiner and $\mathrm{Vt}-\mathrm{W}$, to $84 \%$ for $\mathrm{GCE}$, to $74 \%$ for $\mathrm{C} \& \mathrm{H}$. Cloud ice ranges from $83 \%$ convective in $\mathrm{Vt}-\mathrm{W}$ to just $47 \%$ in $\mathrm{C} \& \mathrm{H}$. Another indication of convection is the presence of graupel or hail. For $\mathrm{Vt}-\mathrm{W}$ and Steiner, $85 \%$ of the hail is convective, for $\mathrm{Xu}$ $68 \%$, for GCE and CA20, about $58 \%$, and for C\&H, only $50 \%$.

In TOGA COARE, cloud water is more variable because significant amounts are present further behind the leading edge. It ranges from just $40 \%$ convective in $\mathrm{C} \& \mathrm{H}$ up to $78 \%$ for VtW. GCE has $54 \%$ convective. GCE, C\&H, and CA20 methods have minimal convective cloud ice (less than 6\%). Xu has a small amount, 12\%, while Steiner and Vt-W have the most at $36 \%$ and $53 \%$, respectively.

\subsection{Contoured Frequency with Altitude Diagrams (CFADs)}

CFADs are frequency distributions at each altitude summed together as a function of height to make a statistical diagram of a particular field (Yuter and Houze 1995b). Steiner et al. (1995) used CFADs of radar reflectivity from Darwin, Australia, to verify their convective-stratiform separation scheme (i.e., the Steiner method). A narrower distribution with peaks at lower magnitudes (especially at low levels) is expected for the stratiform region. They also made CFADs of Doppler derived vertical velocities for a CaPE (Convection and Precipitation/Electrification Experiment) case. These also showed narrower distributions in the stratiform region. The convective CFAD was broad with a significant portion over $5 \mathrm{~m} / \mathrm{s}$.

Reflectivity CFADs were constructed for both PRESTORM and TOGA COARE for each separation technique. In PRESTORM, each method produced a convective CFAD with larger peak modes than their stratiform CFADs--consistent with the results Steiner et al. (1995) used to verify their algorithm. CFADs for Steiner and GCE are shown in Fig. 13a-d. At low 
levels, peak convective modes are close to $50 \mathrm{dBZ}$ for GCE, C\&H, CA20 and Xu, and $45 \mathrm{dBZ}$ for Steiner and Vt-W. The stratiform modes peak at $20 \mathrm{dBZ}$ for GCE, C\&H, CA20, Xu and Steiner and $15 \mathrm{dBZ}$ for $\mathrm{Vt}-\mathrm{W}$. The PRESTORM stratiform CFADs all show evidence of a bright band and evaporation. Evaporation is not seen in the convective CFADs. One distinct difference from Steiner et al. (1995) is that most of the stratiform CFADs in this study are broader than those of the convective region. Steiner and $\mathrm{Vt}-\mathrm{W}$ are an exception.

Reflectivity CFADs for TOGA COARE reveal similar trends. Results for Steiner and GCE are shown in Fig. 13e-h. GCE, C\&H, and Xu have convective peak modes just under 50 $\mathrm{dBZ}$ and peak stratiform modes near $30 \mathrm{dBZ}$. CA20 has a peak convective mode closer to 40 $\mathrm{dBZ}$. The convective CFAD for the CA20 method is now broader than those of GCE, C\&H, and Xu. This can be attributed to the different cell structure between PRESTORM and TOGA COARE. Steiner has convective and stratiform peak modes near 37 and $27 \mathrm{dBZ}$, respectively. $\mathrm{Vt}-\mathrm{W}$ has the smallest convective peak near $35 \mathrm{dBZ}$ and a stratiform peak at $22 \mathrm{dBZ}$. Thus all the methods again produce larger peak values for the convective region. Only CA20, Steiner and $\mathrm{Vt}-\mathrm{W}$ have convective distributions close to being as broad as their stratiform.

Vertical velocity CFADs for PRESTORM are all broader in the convective region though they are overall much narrower than observed in Steiner et al. (1995). The results for Vt-W and GCE are shown in Fig. 14a-d. At $+5 \mathrm{~m} / \mathrm{s}$, the frequency is close to $1 \%$ whereas Steiner et al. (1995) have the frequency over $10 \%$ at mid-levels. Part of the reason for the discrepancy is that this study counts clear air above new convection as part of the convective region which skews the distributions closer to zero. Also, the horizontal domain in Steiner et al. (1995) is much smaller. The vertical velocity CFADs reveal that some of the separation techniques allow a few occurrences of strong vertical velocities in the stratiform region. These include a few updrafts over $15 \mathrm{~m} / \mathrm{s}$ in GCE, Xu, and CA20, and some over $25 \mathrm{~m} / \mathrm{s}$ in C\&H. Steiner contains some stratiform updrafts over $10 \mathrm{~m} / \mathrm{s}$, but Vt-W has no updrafts over $5 \mathrm{~m} / \mathrm{s}$ in 
the stratiform region. These outliers are infrequent and do not affect the overall results, though they appear to be misclassified. Xu (1995), however, states that significant vertical velocities above the melting layer not associated with convective rain rates should be left as stratiform as they are mainly in the upper troposphere. The largest outliers do occur about the freezing level, but they do not satisfy the condition $|w| \ll$ Vice put forth by Houze (1993) and Steiner et al. (1995) where Vice is of the order 1 to $3 \mathrm{~m} / \mathrm{s}$. The widest convective and narrowest stratiform CFADs are from $\mathrm{Vt}-\mathrm{W}$ followed by Steiner then the others.

CFADs of vertical velocities for the TOGA COARE case, though slightly narrower, show similar characteristics compared to PRESTORM. Results for the GCE and Vt-W methods are shown in Fig. 14e-h. Again, the Steiner and Vt-W methods have the broadest convective CFADs and the narrowest stratiform.

\subsection{Microphysical Processes}

In addition to CFADs of vertical velocity and reflectivity, another type of contoured diagram was made using microphysical data from the model. These diagrams, termed CDADs for Cumulative Distribution by Altitude Diagrams, were constructed by partitioning the microphysical processes of condensation, evaporation, deposition, sublimation, freezing and melting according to vertical velocity bins (the same used in the vertical velocity CFADs) as a function of height, for the entire domain, cumulatively. Each bin is normalized by the total cumulative value for that process so that the diagrams show as a function of $\mathrm{W}$ and $\mathrm{Z}$ the distribution of where a process occurs. Results for the total domain are shown in Fig. 15. The distributions for each process were also partitioned into convective and stratiform for each separation technique. The results are in Tables 5 and 6 . The PRESTORM results are discussed first. 
In PRESTORM, the majority of condensation occurs between updrafts of 2 and $14 \mathrm{~m} / \mathrm{s}$ between 1.5 and $6 \mathrm{~km}$. All the techniques classify condensation as convective, from $72 \%$ in $\mathrm{C} \& \mathrm{H}$ to over $97 \%$ in Steiner and Vt-W. Evaporation can be separated into two distinct regimes. In the convective regime, evaporation extends from the surface to $6 \mathrm{~km}$ with a significant portion from downdrafts stronger than $-3 \mathrm{~m} / \mathrm{s}$. This is attributed to downdrafts along the periphery of rising updraft cores. The stratiform regime is narrower, confined below $4 \mathrm{~km}$, and is centered on zero $\mathrm{m} / \mathrm{s}$. This evaporation is due to rain falling beneath the anvil. Evaporation ranges from about half convective in $\mathrm{GCE}, \mathrm{C} \& \mathrm{H}$, and $\mathrm{CA} 20$ up to $80 \%$ convective in $\mathrm{Vt}-\mathrm{W}$.

Deposition occurs mainly between 5 and $12 \mathrm{~km}$. Though skewed towards weaker updrafts, a significant portion extends past $10 \mathrm{~m} / \mathrm{s}$. Deposition occurs below about $5 \mathrm{~m} / \mathrm{s}$ in the stratiform region; the convective portion is centered between 5 and $7.5 \mathrm{~m} / \mathrm{s}$ and extends past 10 $\mathrm{m} / \mathrm{s}$. Deposition ranges from $31 \%$ convective in $\mathrm{C} \& \mathrm{H}$ to $57 \%$ in $\mathrm{Vt}-\mathrm{W}$. Sublimation primarily occurs between 4 and $11 \mathrm{~km}$ in weak downdrafts. It ranges from just $17 \%$ convective in $\mathrm{C} \& \mathrm{H}$ to $34 \%$ in $\mathrm{Vt}-\mathrm{W}$.

All of the techniques consider freezing to be a convective process from $77 \%$ in $\mathrm{C} \& \mathrm{H}$ to $98 \%$ in Steiner and Vt-W. The distribution extends from the freezing level near $4 \mathrm{~km}$ up to 9 $\mathrm{km}$. At stronger updrafts, freezing occurs mainly within $1 \mathrm{~km}$ of the freezing level. Melting varies from $56 \%$ convective in $\mathrm{C} \& \mathrm{H}$ to $87 \%$ in Steiner. It mostly occurs within $3 \mathrm{~km}$ of the melting level between -5 and $5 \mathrm{~m} / \mathrm{s}$, but a small convective tail extends out to $15 \mathrm{~m} / \mathrm{s}$ just below 4 $\mathrm{km}$.

In TOGA COARE, the variation is considerably higher. Again, condensation is predominantly convective, but it now ranges from $55 \%$ convective in $\mathrm{C} \& \mathrm{H}$ to $90 \%$ in Vt-W. Except for Vt-W, the percentage of convective condensation is at least $15 \%$ lower per method 
compared to PRESTORM. The distribution also differs from PRESTORM. It has two peaks at low levels that merge into a single peak at mid-levels. The convective portion has an ascending axis from $10 \mathrm{~m} / \mathrm{s}$ at $2 \mathrm{~km}$ up to $1 \mathrm{~m} / \mathrm{s}$ at $4 \mathrm{~km}$. The stratiform portion is near $0 \mathrm{~m} / \mathrm{s}$ and extends up to $8 \mathrm{~km}$ with a peak near $4 \mathrm{~km}$ at $1 \mathrm{~m} / \mathrm{s}$. The separation methods all produce the same pattern. There is considerable variation in the partitioning of evaporation. $\mathrm{C} \& \mathrm{H}$ has it $52 \%$ convective and Vt-W $81 \%$. Evaporation extends from the surface to $8 \mathrm{~km}$ and centers along $0 \mathrm{~m} / \mathrm{s}$.

There is immense diversity in the partitioning of deposition. $\mathrm{C} \& \mathrm{H}$ has only $4 \%$ convective while Vt-W has $68 \%$. The distribution lies between 5 and $13 \mathrm{~km}$ and skews towards zero. Among the methods with a meaningful convective amount, the convective part is broader. The stratiform portion is narrow and tall. Sublimation likewise shows a tremendous variation varying from $3 \%$ convective in $\mathrm{C} \& \mathrm{H}$ to $49 \%$ in $\mathrm{Vt}-\mathrm{W}$. The distribution is fairly symmetrical about $0 \mathrm{~m} / \mathrm{s}$ and extends from 4 to $13 \mathrm{~km}$.

As with condensation, freezing is far less convective in TOGA COARE. It varies enormously from $24 \%$ convective in $\mathrm{C} \& \mathrm{H}$ to $92 \%$ in $\mathrm{Vt}-\mathrm{W}$. The biggest changes occurred in $\mathrm{C} \& \mathrm{H}$ and GCE with very little change in $\mathrm{Vt}-\mathrm{W}$. The distribution is very broad base just above the freezing level then narrows up to $10 \mathrm{~km}$. A big difference between PRESTORM and TOGA COARE involves melting. All methods have much lower convective percentages in TOGA COARE, $5 \%$ in C\&H to $61 \%$ in Vt-W. The greatest reduction is in C\&H, GCE, Xu and CA20 and is on the order of $40 \%$ or more. Steiner and Vt-W are also noticeably reduced. Thus melting occurs mainly in the convective region in PRESTORM and in the stratiform region in TOGA COARE.

\subsection{Latent Heating Retrieval}


One major current application of convective-stratiform separation is the retrieval of latent heating profiles from observed rainfall data (Tao et al. 1990; 1993; 2000). The Goddard Convective-Stratiform Heating (CSH) algorithm (Tao et al. 1990; 1993a; 2001) can retrieve latent heating profiles of convective systems using rainfall as a multiplier and stratiform amount as a weighting factor for appropriate rainfall-normalized convective and stratiform heating profiles. The technique relies on the characteristic vertical shapes of latent heating in the convective and stratiform regions of MCSs. The stratiform percentage must be accurate to within 10\% for an accurate retrieval (Tao et al. 1993a), because the level of maximum heating shifts with changing stratiform fraction and $10 \%$ accuracy is sufficient to define the peak level.

The sensitivity of the retrieved heating profiles to the choice of separation technique is shown in Fig. 16. Treating the simulations as substitutes for the real system and using the observed stratiform amount of 29\% (Johnson and Hamilton 1988) for PRESTORM, sample retrievals are produced using the $\mathrm{CSH}$ algorithm. They all show a stratiform bias compared to the true heating profile in the model although the GCE, C\&H, CA20 and Xu based profiles are good approximations. The Vt-W and Steiner based profiles shift the peak heating level too high. Of course, the closer a method was to the chosen percentage of $29 \%$, the better its chance would be of matching the true model heating and is consistent with the results. However, the choice of $29 \%$ is arbitrary in the model and merely serves to show the potential variability of the resulting retrievals.

Applying this same test to TOGA COARE using the model results and the observed 40\% stratiform (Short et al. 1997), the GCE, C\&H, and Xu profiles can reproduce the true model heating. The CA20 and Vt-W profiles are slightly stratiform while Steiner again produces an exaggerated stratiform bias. $\mathrm{GCE}, \mathrm{C} \& \mathrm{H}$, and $\mathrm{Xu}$ were closest to the chosen value of $40 \%$. This does not mean the others will produce poor retrievals. Two different separation methods can yield significantly different stratiform percentages, but rain normalized profiles are 
used. Large heating normalized by a large rain amount can have the same normalized profile as smaller heating normalized by a smaller rain amount as with different size areas. Rainnormalized heating profiles for each method for both cases are shown in Fig. 17.

The PRESTORM convective profiles are quite uniform, but not the stratiform profiles. The Vt-W and Steiner stratiform profiles have exaggerated amplitudes. This is a result of heating in the non-surface-precipitating anvil combined with the heating from the precipitating anvil being normalized by small stratiform rain amounts. This can greatly impact the retrieved profiles. The TOGA COARE stratiform profiles show similar behavior only this time the CA20 and Steiner profiles appear amplified. The Vt-W profiles in TOGA COARE have a shape different from the rest that is not simply due to division by a smaller denominator.

\subsection{Summary and Conclusions}

Six different convective-stratiform separation techniques were compared and evaluated using 2D numerical simulations of a tropical (TOGA COARE) and midlatitude continental (PRESTORM) squall line. The six techniques were based on: Churchill and Houze (1984), Tao et al. (1993b), Xu (1995), a constant area (e.g. Caniaux 1994), Steiner et al. (1995), and a new Vt-W method based on the premise that hydrometeor fall speedslocity are large relative to air velocity in stratiform precipitation (Houghton 1968; Steiner el al. 1995; Houze 1997). The results of applying the different separation techniques to rainfall, mass flux, Q1, Q2, hydrometeors, microphysics and latent heating retrieval were assessed. Overall, $\mathrm{C} \& \mathrm{H}$ and GCE were found to produce the most stratiform results and Steiner and Vt-W the most convective. Observational comparisons were not sufficient to justify using one particular technique over the others.

Stratiform rain estimates varied significantly in both PRESTORM and TOGA COARE. 
Johnson and Hamilton (1988) found 29\% stratiform rain for the PRESTORM case using gauge data making all of the techniques appear to underestimate the stratiform rain. However, using the convective rainrate threshold from Johnson and Hamilton (1988) in the model results in a stratiform amount of just $4 \%$ which agrees well with the lowest estimate given by Steiner. Eventhough the gauge threshold is applied differently in the model, it indicates the model likely underestimates the frequency of light rainrates as was found by Sui et al. (1998) making it hard to evaluate the methods in the model based on comparisons with observed values. Short et al. (1997) found rainfall to be $40 \%$ stratiform during active periods in TOGA COARE. This agreed well with $\mathrm{C} \& \mathrm{H}, \mathrm{GCE}$ and $\mathrm{Xu}$ in the model. However, the same caveats apply to the model rainrates. All of the techniques found larger stratiform amounts in the tropical case.

The average convective width, with coherence, in PRESTORM and in TOGA COARE was found to be very close to the mean $\mathrm{CA} 20$ values suggesting the assumed characteristic convective width of $20 \mathrm{~km}$ in CA20 was a reasonable approximation.

In PRESTORM, the six techniques produced convective and stratiform mass flux profiles with similar characteristic shapes, but peak levels and magnitudes varied a great deal. In TOGA COARE, the techniques showed less variation at low levels where peak levels were nearly uniform. Differences mainly occurred aloft as low-level vertical motion was weak behind the leading edge. C\&H, GCE, and CA20 assigned nearly all of the net upward mass flux aloft as stratiform while increasingly $\mathrm{Xu}$, Steiner and $\mathrm{Vt}-\mathrm{W}$ assigned it as convective, altering the shape of the convective $\mathrm{Vt}-\mathrm{W}$ profile. Qualitatively the techniques agreed but differed greatly in magnitude.

In PRESTORM, qualitatively the techniques produced very similar convective and stratiform Q1 profiles. The only significant differences were in the magnitude of the midlevel peaks. In TOGA COARE, the variation at low levels was minimal but quite large aloft. $\mathrm{C} \& \mathrm{H}$, 
GCE, and CA20 assigned most of the heating aloft as stratiform, while Vt-W assigned most of it as convective. The variation in the Q2 profiles was significant in PRESTORM at low levels and in TOGA COARE at mid-levels.

Despite being the only method to use hydrometeors, GCE had no more convective cloud or cloud ice relative to the others than would be expected from the overall stratiform rain percentage. All of the methods found cloud water to be overwhelmingly convective in PRESTORM, but cloud ice varied. In TOGA COARE, the variation in convective cloud water was large. Cloud ice was mostly stratiform.

In both PRESTORM and TOGA COARE, each method was able to produce reflectivity CFADs with larger convective peak frequencies but not necessarily broader convective distributions. Each method had vertical velocity CFADs in both cases that were broader for the convective region. Vt-W produced the narrowest stratiform vertical velocity CFAD followed by $\mathrm{Xu}$ and Steiner. The stratiform CFADs also showed instances of misclassified points.

Modified CFADs or CDADs were constructed to show how microphysical processes were distributed as a function of $\mathrm{W}$ and $\mathrm{Z}$. The processes were distributed over a wider velocity and vertical range in the midlatitude case. The processes were also partitioned into convective and stratiform for each method. The results varied moderately in PRESTORM though there was general agreement as to the character of each process. Condensation, most evaporation, freezing and melting were convective with sublimation and most deposition stratiform. In TOGA COARE the variation was immense. Condensation was convective, and sublimation was stratiform. But there was disagreement on evaporation, deposition, freezing and melting.

Latent heating retrieval was found to be quite sensitive to the use of separation technique. This was mainly attributed to the stratiform region especially for methods that found 
very little stratiform rain (i.e., Steiner and Vt-W).

Overall, the different separation techniques produced results that qualitatively agreed. However, the quantitative differences were could be substantial. Most of the differences can be attributed to the transition area, where significant vertical motion exists only aloft. $\mathrm{C} \& \mathrm{H}$ is the most likely to treat it as stratiform, and Vt-W the most likely to treat it as convective. As cells move from the leading edge of the system rearward, it can be very arbitrary when to change their designation from convective to stratiform. Therefore, it may be useful to make "transition" a third category in the separation of MCSs. Many separation techniques look for convective criteria only below the melting level. In the future the convective region could be defined as that where convective criteria are exceeded below the melting level, and the transition region as that where convective criteria are only exceeded above the melting level. Another approach would be to have a classification that allows for a weighted fraction rather than a binary distinction.

\section{Acknowledgments}

This work is supported by the NASA Headquarters Atmospheric Dynamics and Thermodynamics Program and by the NASA TRMM project. These authors are grateful to Dr. R. Kakar (NASA/HQ) for his support of this research and to Dr. W. Olson for providing the code for the Steiner et al. (1995) separation technique. Acknowledgment is also made to NASA/Goddard Space Flight Center for computer time used in the research.

\section{References}

Adler, R.F., and A.J. Negri, 1988: A satellite infrared technique to estimate tropical convective and stratiform rainfall. J. Appl. Meteor., 27, 30-51. 
Alexander, G.D., and W.R. Cotton, 1998: The use of cloud-resolving simulations of mesoscale convective systems to build a mesoscale parameterization scheme. J. Atmos. Sci., 55, 2137 2161.

Atlas, D., Ed., 1990: Radar in meteorology. American Meteorological Society, 806 pp.

Battan, L.J., 1973: Radar observation of the atmosphere. The University of Chicago Press, 161 pp.

Brown, R.M., 1979: Mesoscale unsaturated downdrafts driven by rainfall evaporation: A numerical study. J. Atmos. Sci., 36, 313-335.

Byers, H.R., and R.R. Braham Jr., 1949: The Thunderstorm. U.S. Government Printing Office, $287 \mathrm{pp}$.

Caniaux, G., J.-L. Redelsperger, and J.-P. Lafore, 1994: A numerical study of the stratiform region of a fast-moving squall line. Part I: General description and water and heat budgets. J. Atmos. Sci., 51, 2046-2074.

Chin, H.-N. S., 1994: The impact of the ice phase and radiation on a mid-latitude squall line system. J. Atmos. Sci., 51, 3320-3343.

Churchill, D.D., and R.A. Houze Jr., 1984: Development and structure of winter monsoon cloud clusters on 10 December 1978. J. Atmos. Sci., 41, 933-960.

Fairall, C.W., E.F. Bradley, D.P. Rogers, J.B. Edson, and G.S. Young, 1996: Bulk parameterization of air-sea fluxes for Tropical Ocean Global Atmosphere Coupled Ocean- 
Atmosphere Response Experiment. J. Geophys. Res., 101, 915-929.

Ferrier, B.S., S. Simpson, and W.-K. Tao, 1996: Factors responsible for different precipitation efficiencies between midlatitude and tropical squall simulations. Mon. Wea. Rev., 124, 2100-2125.

Frank, W.M., and J.L.M. McBride, 1989: The vertical distribution of heating in AMEX and GATE cloud clusters. J. Atmos. Sci., 46, 3464-3478.

Gamache, J.F., and R.A. Houze Jr., 1982: Mesoscale air motions associated with a tropical squall line. Mon. Wea. Rev., 110, 118-135.

Hamilton, R.A., and J.W. Archbold, 1945: Meteorology of Nigeria and adjacent territory. Quart. J. Roy. Meteor. Soc., 71, 231-262.

Houghton, H. G., 1968: On precipitation mechanisms and their artificial modification. J. Appl. Meteor., 7, 851-859.

Houze, R.A., Jr., 1973: A climatological study of vertical transports by cumulus- scale convection. J. Atmos. Sci., 30, 1112-1123.

Houze, R.A., Jr., 1977: Structure and dynamics of a tropical squall-line system. Mon. Wea. Rev., 105, 1540-1567.

Houze, R.A., Jr., 1982: Cloud clusters and large-scale vertical motions in the tropics. J. Meteor. Soc. Japan, 60, 396-410. 
Houze, R.A., Jr., 1993: Cloud Dynamics. Academic Press, 573 pp.

Houze, R.A., Jr., 1997: Stratiform precipitation in regions of convection: a meteorological paradox? Bull. Amer. Met. Soc., 78, 2179-2196.

Johnson, D., W.-K. Tao, J. Simpson, and C.-H. Sui, 2001: A study of the response of deep tropical clouds to mesoscale processes, Part I: Modeling strategy and simulation of TOGA COARE convective systems, J. Atmos. Sci.. (submitted).

Johnson, R.H., 1984: Partitioning tropical heat and moisture budgets into cumulus and mesoscale components: Implications for cumulus parameterization. Mon. Wea. Rev., 112, 1590-1601.

Johnson, R.H., and P.J. Hamilton, 1988: The relationship of surface pressure features to the precipitation and airflow structure of an intense midlatitude squall line. Mon. Wea. Rev., $116,1444-1472$.

Johnson, R.H., and G.S. Young, 1983: Heat and moisture budgets of tropical mesoscale anvil clouds. J. Atmos. Sci., 40, 2138-2147.

Jorgensen, D.P., M.A. LeMone, and S.B. Trier, 1997: Structure and evolution of the 22 February 1993 TOGA-COARE squall line: Observations of precipitation, circulation, and surface energy fluxes. J. Atmos. Sci., 54, 1961-1985.

Leary, C.A., and R.A. Houze Jr., 1979: Melting and evaporation of hydrometeors in precipitation from the anvil clouds of deep tropical convection. J. Atmos. Sci., 36, 669-679. 
LeMone, M.A., D.P. Jorgensen, and B.F. Smull, 1994: The impact of two convective systems of sea surface stresses in COARE. Preprints, 6th Conference on Mesoscale Processes, Amer. Meteor. Soc., Portland, 40-44.

Lin, Y.-L., R.D. Farley and H.D. Orville, 1983: Bulk parameterization of the snow field in a cloud model. J. Clim. Appl. Meteor., 22, 1065-1092.

Newton, C.W., 1950: Structure and mechanism of the prefrontal squall line. J. of Meteor., 7, 210-222.

Redelsperger, J.-L., P.R.A. Brown, F. Guichard, C. Hoff, M. Kawasima, S. Lang, Th. Montmerle, K. Nakamura, K. Saito, C. Seman, W.-K. Tao, and L.J. Donner, 2000: A GCSS model intercomparison for a tropical squall line observed during TOGA-COARE. Part I: Cloud-resolving models. Quart. J. Roy. Meteor. Soc., 126, 823-863.

Reed, R.J., and E.E. Recker, 1971: Structure and properties of synoptic-scale wave disturbances in the equatorial western pacific. J. Atmos. Sci., 28, 1117-1133.

Rutledge, S.A., and P.V. Hobbs, 1984: The mesoscale and microscale structure and organization of clouds and precipitation in midlatitude clouds. Part XII: A diagnostic modeling study of precipitation development in narrow cold frontal rainbands. J. Atmos. Sci., 41, 2949-2972.

Rutledge, S.A., R.A. Houze Jr., M.I. Biggerstaff, and T. Matejka, 1988: The Oklahoma-Kansas mesoscale convective system of 10-11 June 1985: Precipitation structure and single-doppler radar analysis. Mon. Wea. Rev., 116, 1409-1430. 
Ryde, J.W., 1946: The attenuation and radar echoes produced at centimeter wavelengths by various meteorological phenomena. Meteorological Factors in Radio Wave Propagation, Physical Society, London, 169-188.

Short, D.A., P.A. Kucera, B.S. Ferrier, J.C. Gerlack, S.A. Rutledge, and O.W. Thiele, 1997: Shipboard Radar Rainfall Patterns within the TOGA COARE IFA. Bull. Amer. Met. Soc., 78, 2817-2836.

Simpson, J., 1980: Downdrafts as linkages in dynamic cumulus seeding effects. J. Appl. Meteor., 19, 477-487.

Simpson, J., R. Adler, and G. North, 1988: A proposed tropical rainfall measuring mission (TRMM) satellite. Bull. Amer. Met. Soc., 69, 278-295.

Simpson, J., and W.-K. Tao, 1993: Goddard Cumulus Ensemble Model. Part II: Applications for studying cloud precipitating processes and for NASA TRMM. Terrestrial, Atmospheric and Oceanic Sciences, 4, 73-116.

Smolarkiewicz, P.K., 1983: A simple positive definite advection scheme with small implicit diffusion. Mon. Wea. Rev., 111, 479-486.

Smolarkiewicz, P.K., 1984: A fully multidimensional positive definite advection transport algorithm with small implicit diffusion. J. Comput. Phys., 54, 325-362.

Smolarkiewicz, P.K., and W.W. Grabowski, 1990: The multidimensional positive advection transport algorithm: nonoscillatory option. J. Comput. Phys., 86, 355-375. 
Soong, S.-T., and Y. Ogura, 1973: A comparison between axisymmetric and slab symmetric cumulus models. J. Atmos. Sci., 30, 879-893.

Steiner, M., R.A. Houze Jr., and S.E. Yuter, 1995: Climatological characterization of threedimensional storm structure from operational radar and rain gauge data. J. Appl. Meteor., 34, 1978-2007.

Sui, C.-H., X. Li, and K.-M. Lau, 1998: Radiative-convective processes in simulated diurnal variations of tropical oceanic convection. J. Atmos. Sci., 55, 2345-2357.

Tao, W.-K., and J. Simpson, 1984: Cloud interactions and merging: numerical simulations. J. Atmos. Sci., 41, 2901-2917.

Tao, W.-K., and S.-T. Soong, 1986: A study of the response of deep tropical clouds to mesoscale processes: Three-dimensional numerical experiments. J. Atmos. Sci., 43, 26532676.

Tao, W.-K., and J. Simpson, 1989: Modeling study of a tropical squall-type convective line. J. Atmos. Sci., 46, 177-202.

Tao, W.-K., and J. Simpson, 1993: Goddard Cumulus Ensemble Model. Part I: Model description. Terrestrial, Atmospheric and Oceanic Sciences, 4, 35-72.

Tao, W.-K., S. Lang, J. Simpson, and R. Adler, 1993a: Retreival algorithms for estimating the vertical profiles of latent heat release: Their applications for TRMM. J. Meteor. Soc. Japan, 71, 685-700. 
Tao, W.-K., J. Simpson, C.-H. Sui, B. Ferrier, S. Lang, J. Scala, M.-D. Chou, and K. Pickering, 1993b: Heating, moisture, and water budgets of tropical and midlatitude squall lines: Comparisons and sensitivity to longwave radiation. J. Atmos. Sci., 50, 673-690.

Tao, W.-K., S. Lang, J. Simpson, C.-H. Sui, B. Ferrier, and M.-D. Chou, 1996: Mechanisms of cloud-radiation interaction in the tropics and midlatitudes. J. Atmos. Sci., 53, 2624-2651.

Tao, W.-K., S. Lang, J. Simpson, W.S. Olson, D. Johnson, B. Ferrier, C. Kummerow, and R. Adler, 2000: Vertical profiles of latent heat release and their retrieval for TOGA COARE convective systems using a cloud resolving model, SSM/I, and ship-borne radar data. J. Meteor. Soc. Japan, 78, 333-355.

Trier, S.B., W.C. Skamarock, M.A. LeMone, D.B. Parsons, and D.P. Jorgensen, 1996: Structure and evolution of the 22 February 1993 TOGA-COARE squall line: numerical simulations. J. Atmos. Sci., 53, 2861-2886.

Trier, S.B., W.C. Skamarock, and M.A. LeMone, 1997: Structure and evolution of the 22 February 1993 TOGA-COARE squall line: Organization mechanisms inferred from numerical simulation. J. Atmos. Sci., 54, 386-407.

Wang, Y., W.-K. Tao, and J. Simpson, 1996: The impact of a surface layer on a TOGA COARE cloud system development. Mon. Wea. Rev., 124, 2753-2763.

Wang, Y., W.-K. Tao, J. Simpson, and S. Lang, 2000: The sensitivity of tropical squall lines to surface fluxes: cloud resolving model simulations. Quart. J. Roy. Meteor. Soc., (submitted) 
Wescott, N., 1984: A historical perspective on cloud mergers. Bull. Amer. Meteor. Soc., 65, 219-226.

Xu, K.-W., 1995: Partioning mass, heat, and moisture budgets of explicitly simulated cumulus ensembles into convective and stratiform components. J. Atmos. Sci., 52, 1-23.

Yanai, M., S. Esbensen, and J.-H. Chu, 1973: Determination of bulk properties of tropical cloud clusters from large-scale heat and moisture budgets. J. Atmos. Sci., 30, 611-627.

Yuter, S.E. and R.A. Houze Jr., 1995b: Three-dimensional kinematic and micro- physical evolution of Florida cumulonimbus. Part II: Frequency distributions of vertical velocity, reflectivity, and differential reflectivity. Mon. Wea. Rev., 123, 1941-1963.

Zipser, E.J., 1977: Mesoscale and convective-scale downdrafts as distinct components of squallline structure. Mon. Wea. Rev., 105, 1568-1589. 


\section{TABLES}

Table 1 Characteristics of the large-scale environments associated with the PRESTORM and TOGA COARE squall line cases. Simulation domain size, grid spacing and references are also listed.

Table 2 Main criteria used by the six different separation algorithms to partition convective and stratiform regions. "Gradient" refers to the use of horizontal gradients.

Table 3 Total accumulated rainfall $(\mathrm{mm})$ per grid over all 12 hours of simulation time for both the PRESTORM and TOGA COARE cases. Mean stratiform percentages for each separation technique are listed. Values in parentheses are over the last 4 hours of the simulation.

Table 4 Mean width $(\mathrm{km})$ of the convective and stratiform regions over 12 hours of simulation for each separation method and the average for both PRESTORM and TOGA COARE.

Table 5 Total mean percentage of the microphysical processes that are convective according to each separation technique for the PRESTORM simulation.

Table 6 Total mean percentage of the microphysical processes that are convective according to each separation technique for the TOGA COARE simulation. 


\section{FIGURE CAPTIONS}

Fig. 1. Vertical cross-sections of model estimated radar reflectivity after 720 minutes of simulation for the (a) PRESTORM and (b) TOGA COARE case. Convective regions for each of the separation techniques are overlayed in solid black lines. Traces of the corresponding surface rainrates $(\mathrm{mm} / \mathrm{h})$ are also overlayed (domain top $=200 \mathrm{~mm} / \mathrm{h}$.

Fig. 2. Time-domain cross-sections of surface rainfall rates for the (a) PRESTORM and (b) TOGA COARE case.

Fig. 3. Time series of instantaneous grid averaged total (solid) and stratiform (dashed) rainrate for the (a) PRESTORM and (b) TOGA COARE case.

Fig. 4. Vertical profiles of mean cloud coverage as a percentage of the horizontal domain for both the PRESTORM and TOGA COARE cases.

Fig. 5. Vertical profiles of domain average accumulated mass flux for the total (heavy dash), convective (solid) and stratiform (dotted) regions for both the (a) PRESTORM and (b) TOGA COARE cases.

Fig. 6. Vertical profiles of domain average accumulated convective and stratiform mass flux for each of the six separation techniques for the (a) PRESTORM and (b) TOGA COARE cases. (C\&H - black dashed, GCE - solid black, Xu - gray dotted, CA20 solid gray, Steiner - black dotted, Vt-W - "\#")

Fig. 7. Vertical profiles of rain normalized domain average apparent heating (Q1) for the 
total (heavy dash), convective (solid) and stratiform (dotted) regions for both the (a) PRESTORM and (b) TOGA COARE case.

Fig. 8. Vertical profiles of rain normalized Q1 components for the (a) PRESTORM convective region, (b) PRESTORM anvil region, (c) TOGA COARE convective region, and (d) TOGA COARE anvil region. (Condensation - solid, Deposition - thin solid, Evaporation - dotted, Sublimation - thin dotted, Freezing/Melting - thick dashed, Eddy flux - "e", Radiation - "+")

Fig. 9. Vertical profiles of rain normalized domain average convective and stratiform $\mathrm{Q} 1$ for each of the six separation techniques for the (a) PRESTORM and (b) TOGA COARE case. Line patterns follow Fig. 6.

Fig. 10. Vertical profiles of rain normalized domain average apparent moistening (Q2) for the total (heavy dash), convective (solid) and stratiform (dotted) regions for both the (a) PRESTORM and (b) TOGA COARE cases.

Fig. 11. Vertical profiles of rain normalized domain average convective and stratiform Q2 for each of the six separation techniques for the (a) PRESTORM and (b) TOGA COARE case. Line patterns follow Fig. 6.

Fig. 12. Vertical profiles of domain average hydrometeor content for the (a) PRESTORM and (b) TOGA COARE case. (Rain - solid black, Cloud - dotted black, Snow - solid gray, Cloud ice - dotted gray, Hail - thick dashed black, Graupel - thick dashed gray)

Fig. 13. Reflectivity CFADs for the (a) PRESTORM convective region using GCE separation, (b) PRESTORM anvil region using GCE separation, (c) PRESTORM 
convective region using Steiner separation, (d) PRESTORM anvil region using Steiner separation, (e) TOGA COARE convective region using GCE separation, (f) TOGA COARE anvil region using GCE separation, (g) TOGA COARE convective region using Steiner separation, (h) TOGA COARE anvil region using Steiner separation.

Fig. 14. Same as Fig. 13 except for vertical velocity and Vt-W separation in place of Steiner.

Fig. 15. Domain total microphysical CDADs of (a) PRESTORM condensation, (b) PRESTORM evaporation, (c) PRESTORM deposition, (d) PRESTORM sublimation, (e) PRESTORM freezing, (f) PRESTORM melting, (g) TOGA COARE condensation, (h) TOGA COARE evaporation, (i) TOGA COARE deposition, (j) TOGA COARE sublimation, (k) TOGA COARE freezing, (l) TOGA COARE melting,

Fig. 16. Simulated profiles of retrieved heating (Q1) for each of the six separation techniques applied to model data but using observed stratiform percentages for (a) PRESTORM and (b) TOGA COARE. The actual model heating is shown by the thick solid black line. Line patterns follow Fig. 6.

Fig. 17. Convective and stratiform heating profiles normalized by their respective rainfall amounts for each of the six separation techniques for the (a) PRESTORM convective region, (b) PRESTORM anvil region, (c) TOGA COARE convective region, and (d) TOGA COARE anvil region. 


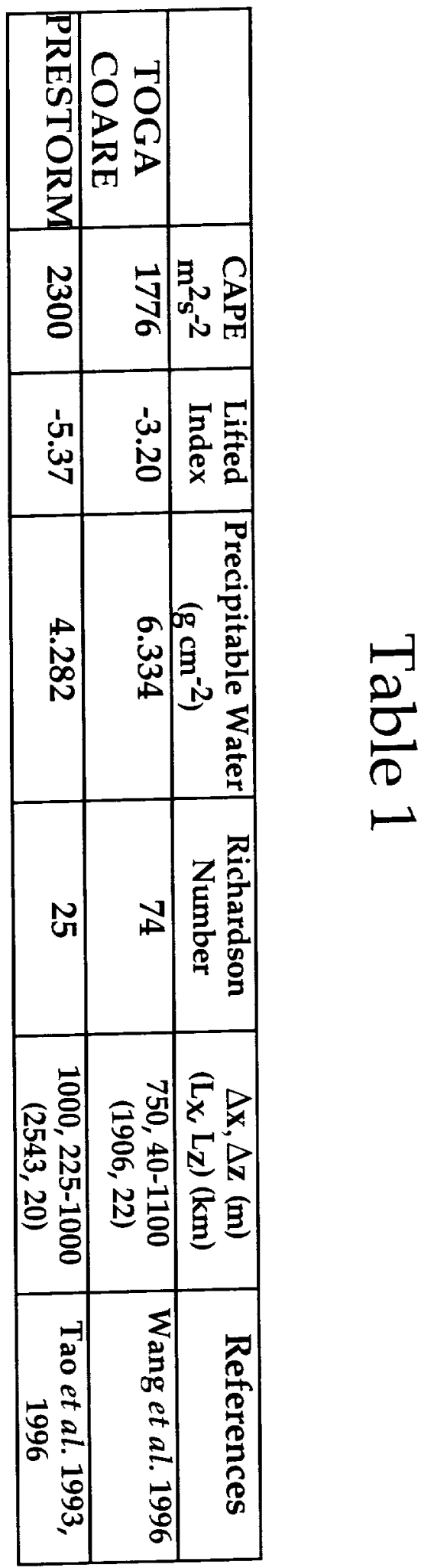




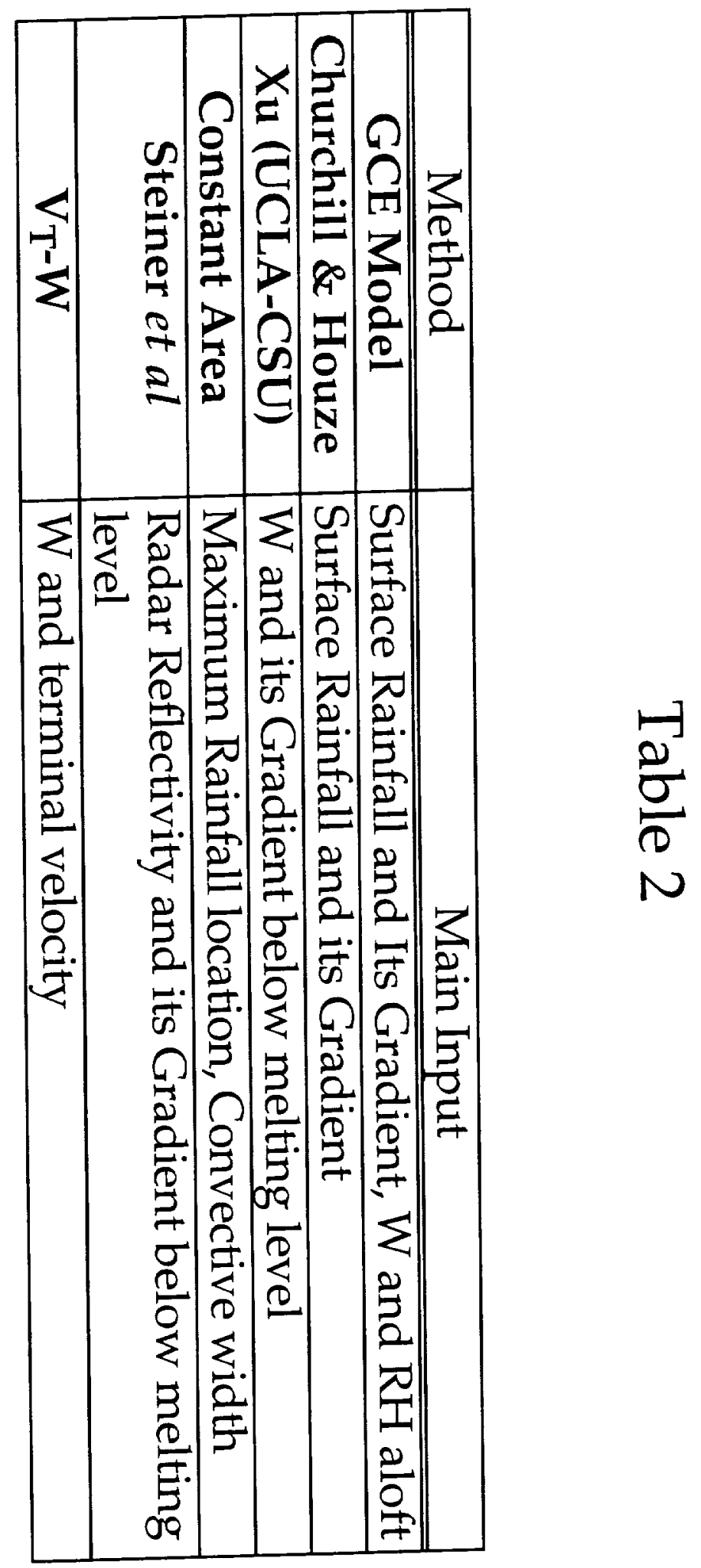




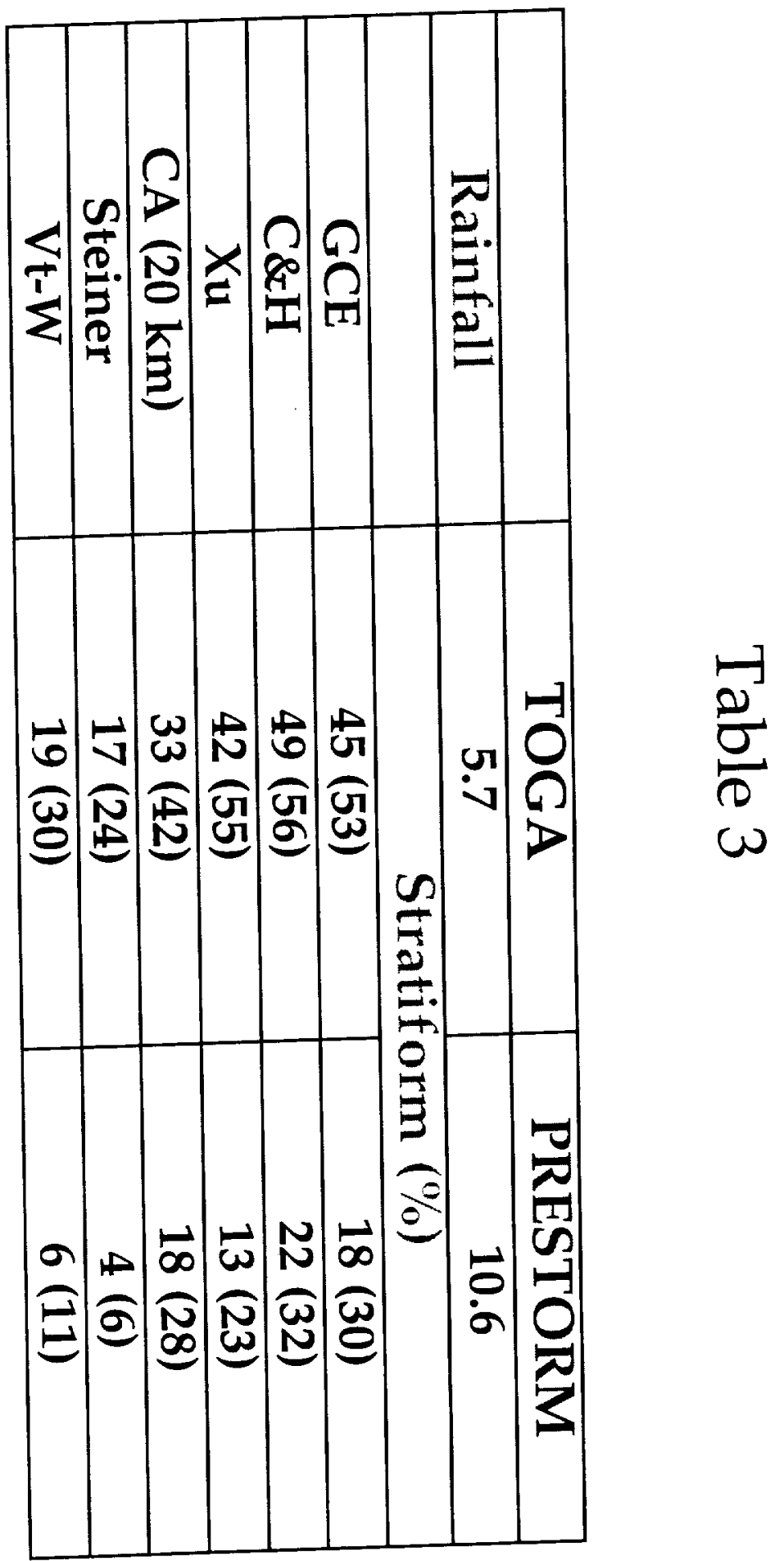




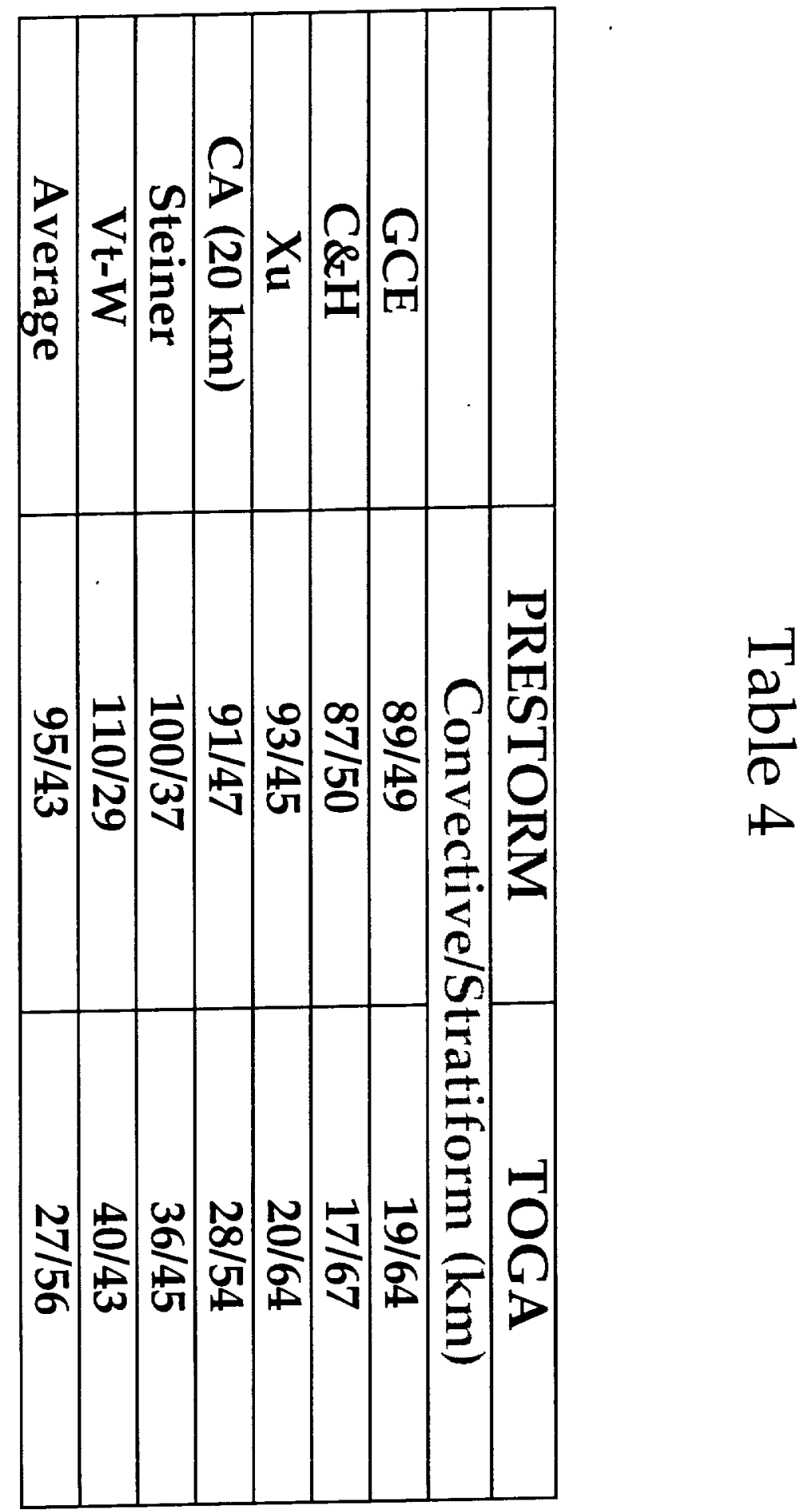




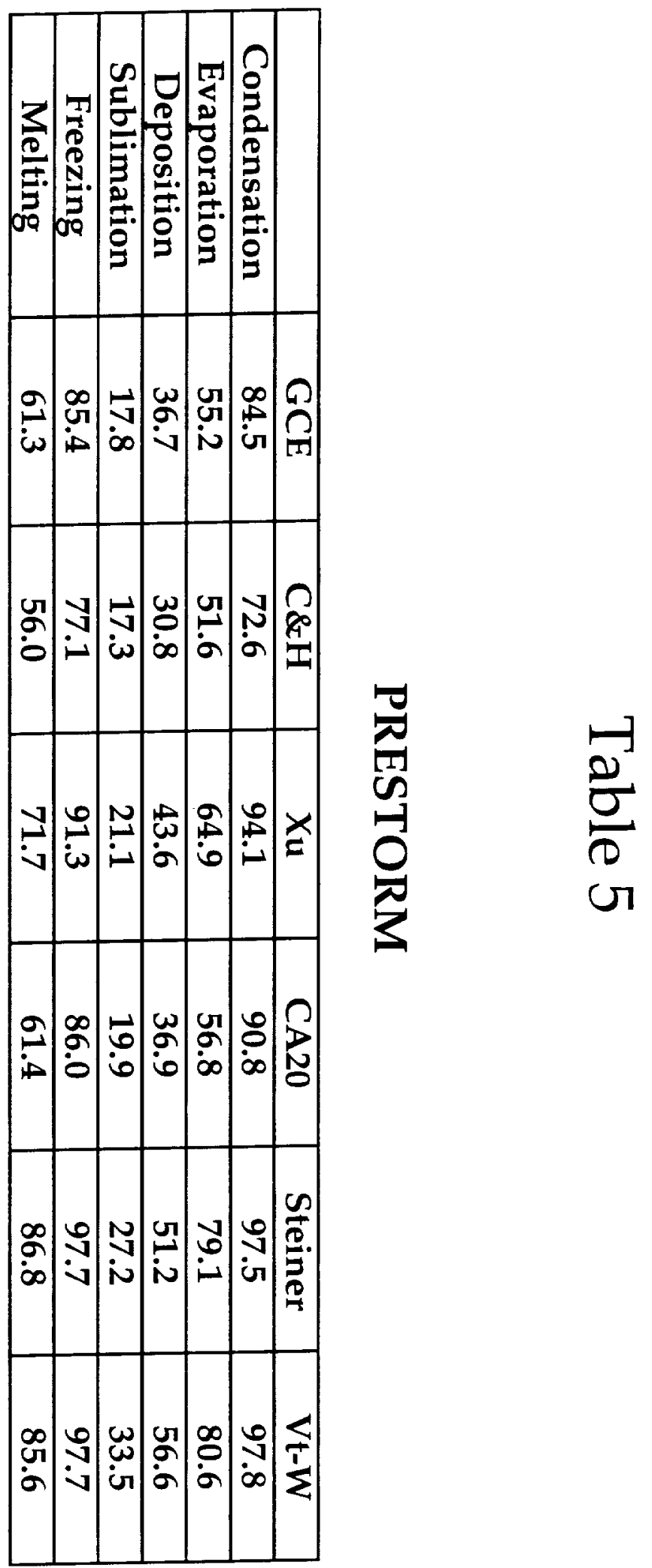




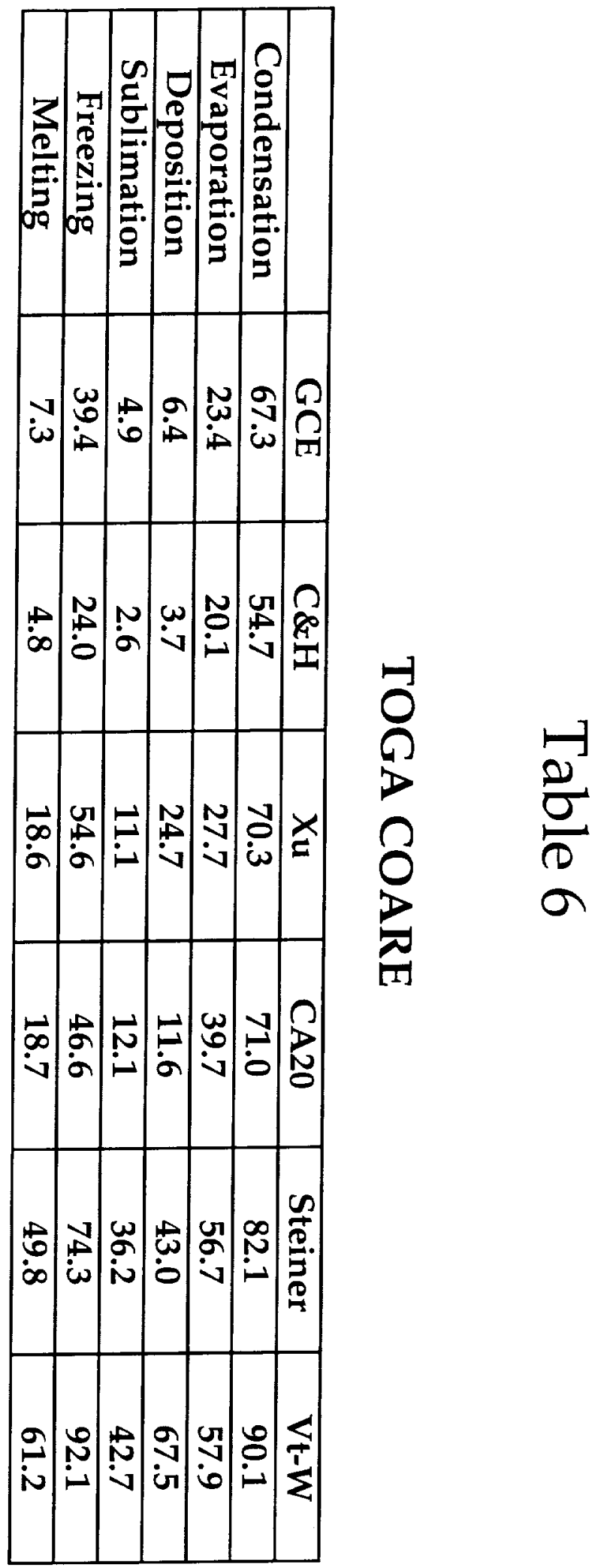



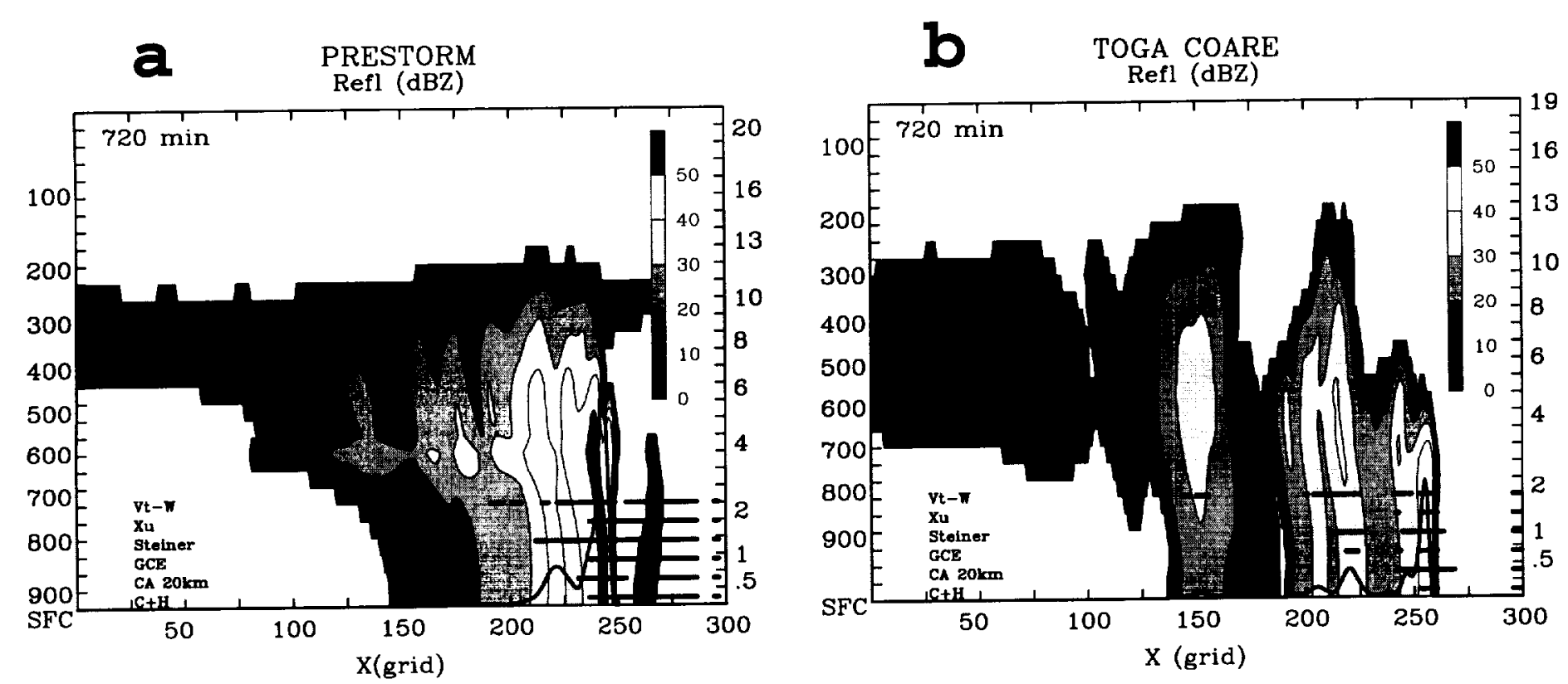


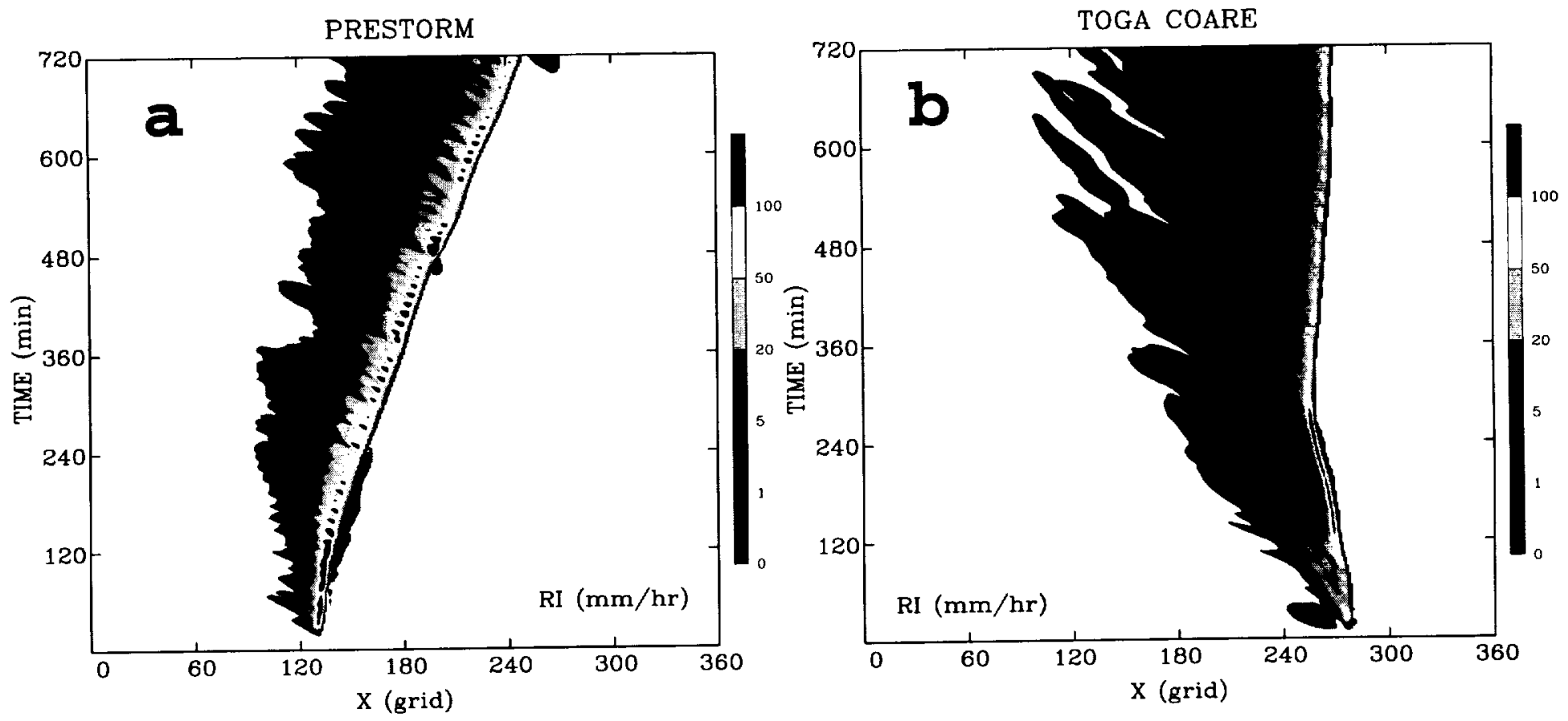

Fig 2 

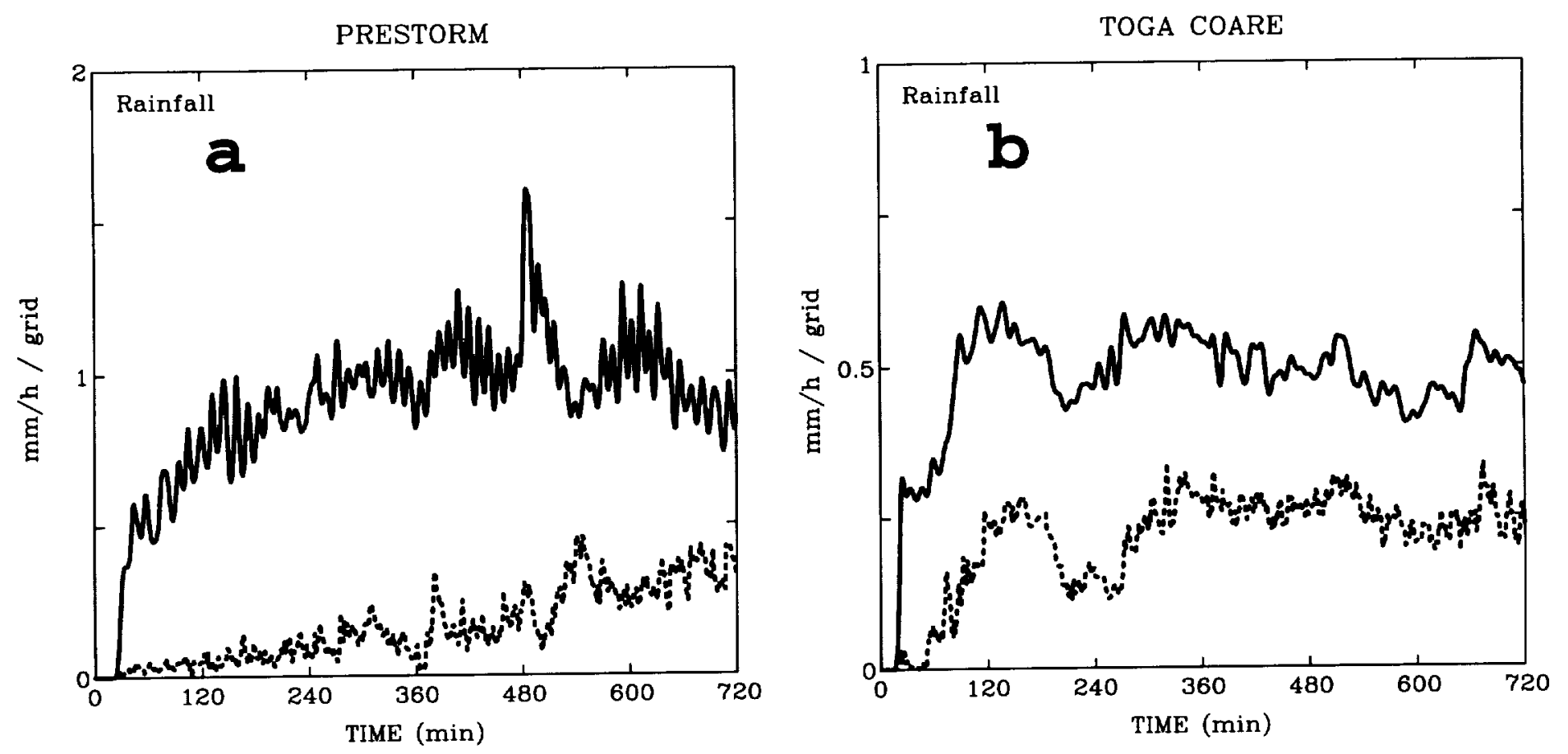

$F / G 3$ 


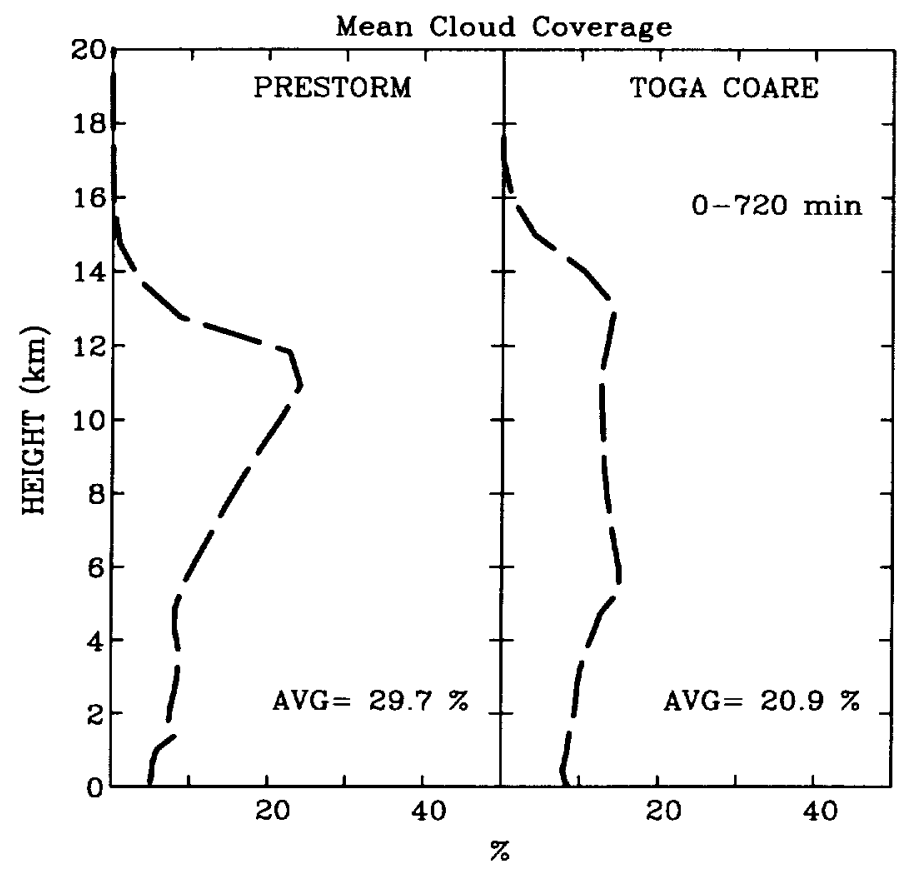

Fig 4 

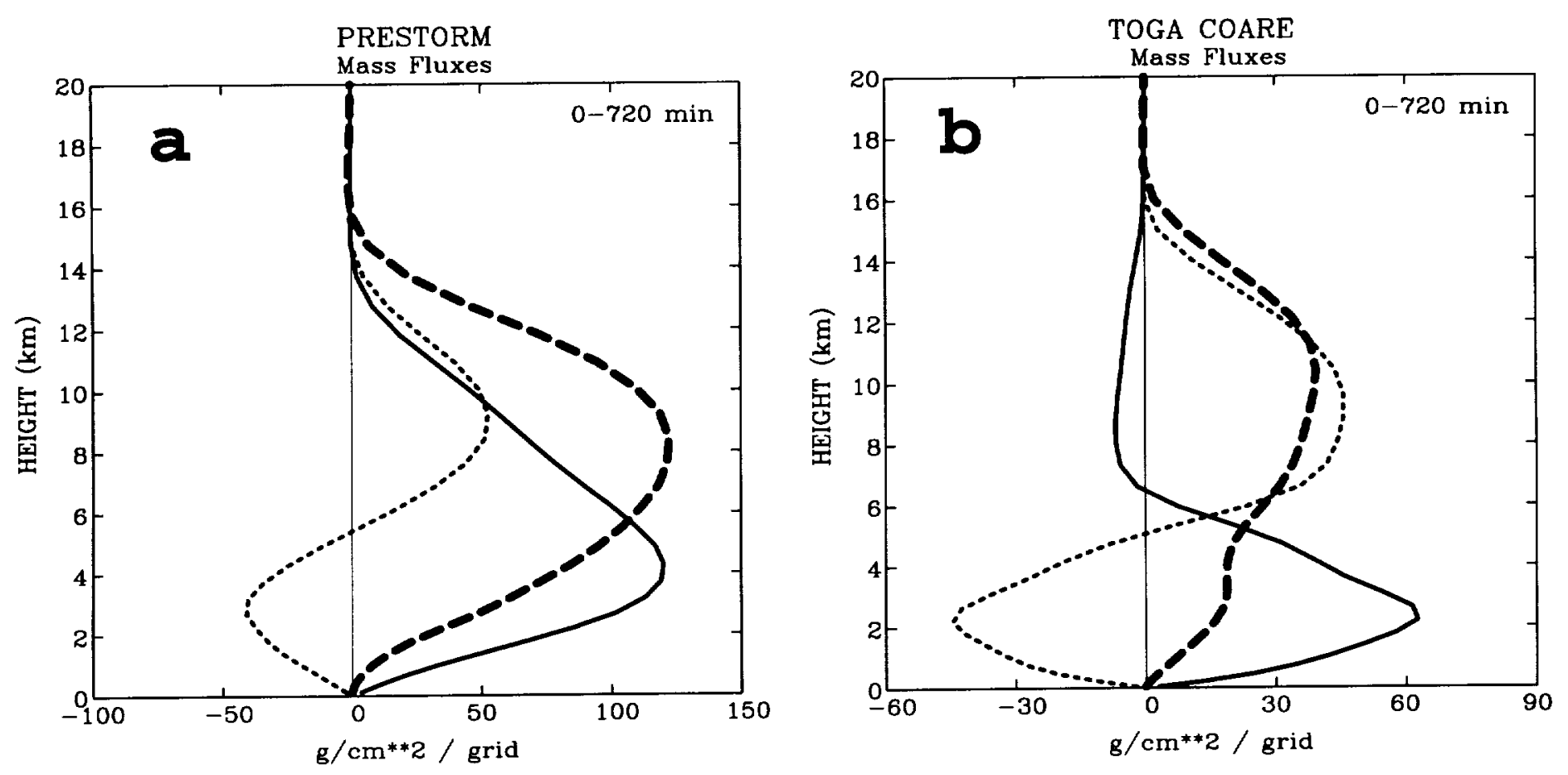

Fig 5 

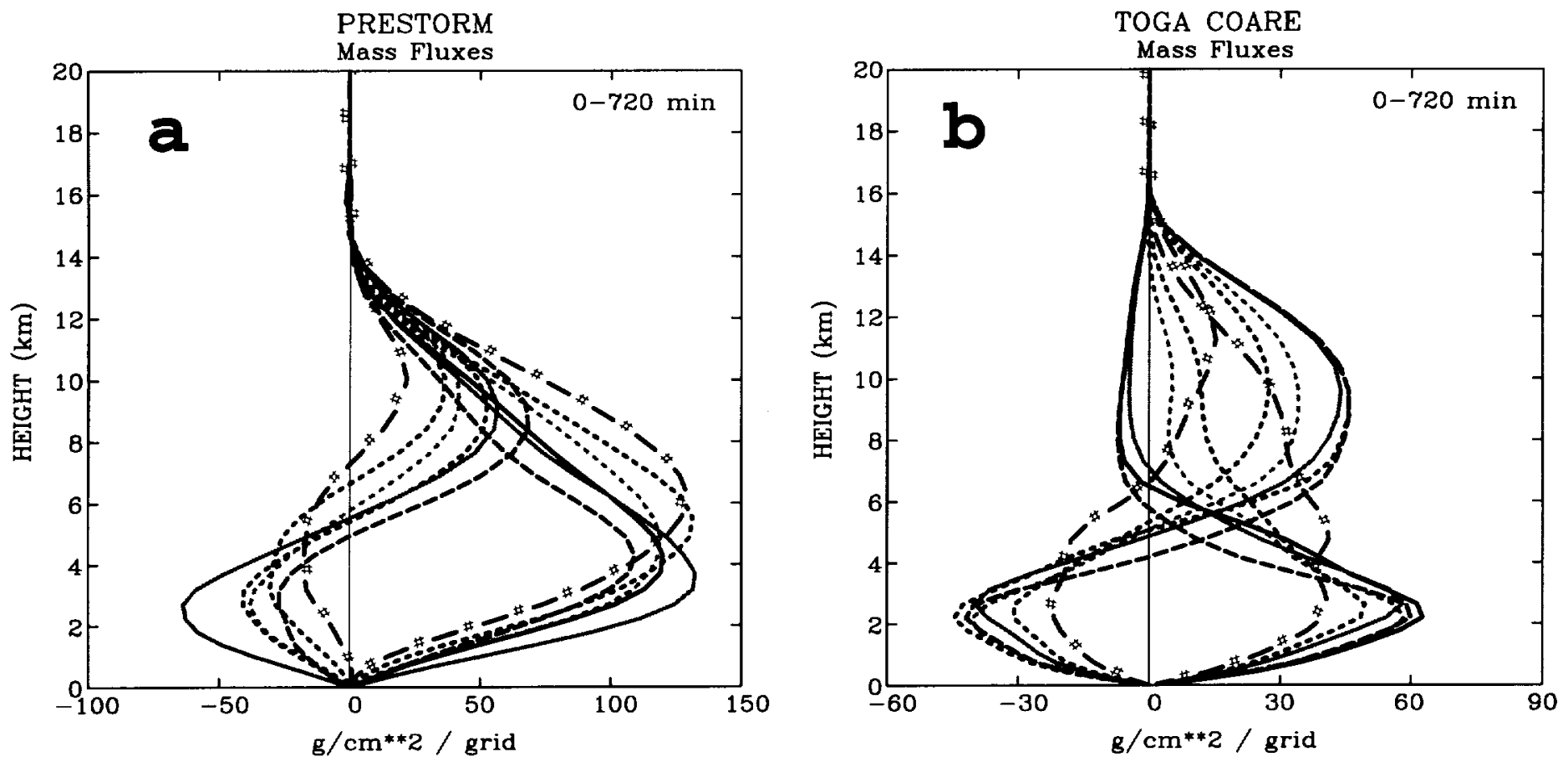

Fig 6 

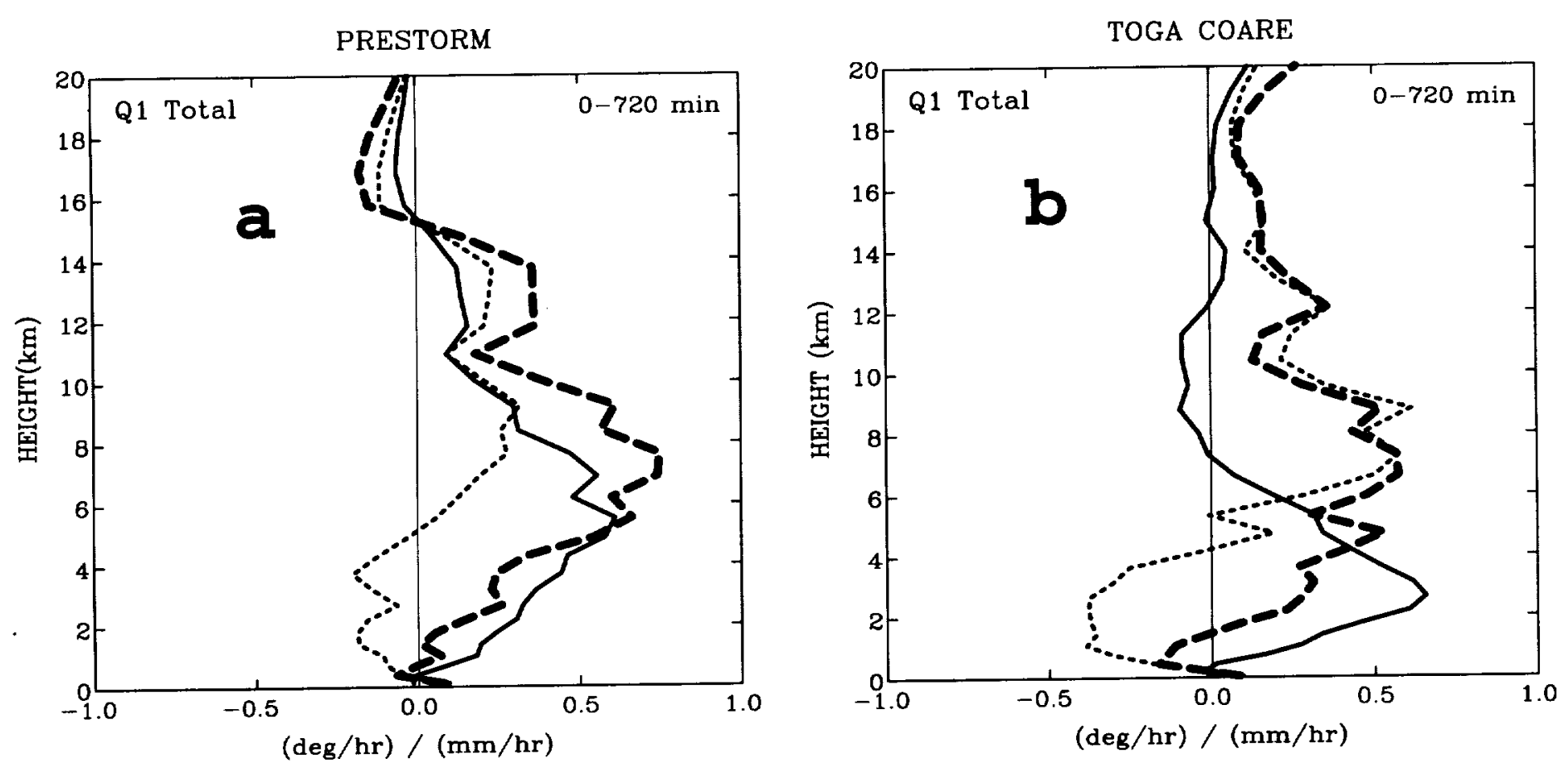

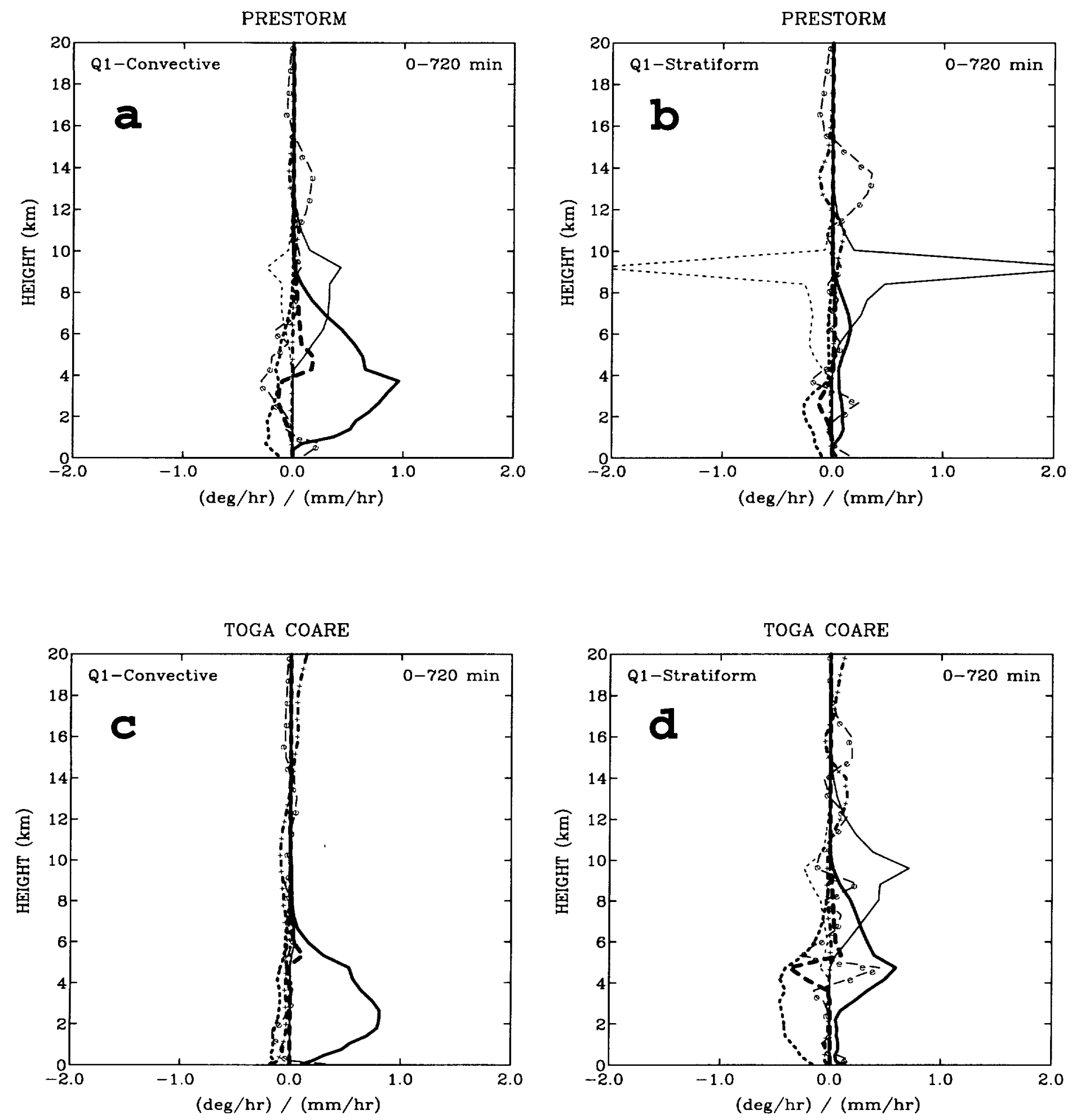

Fig 8 

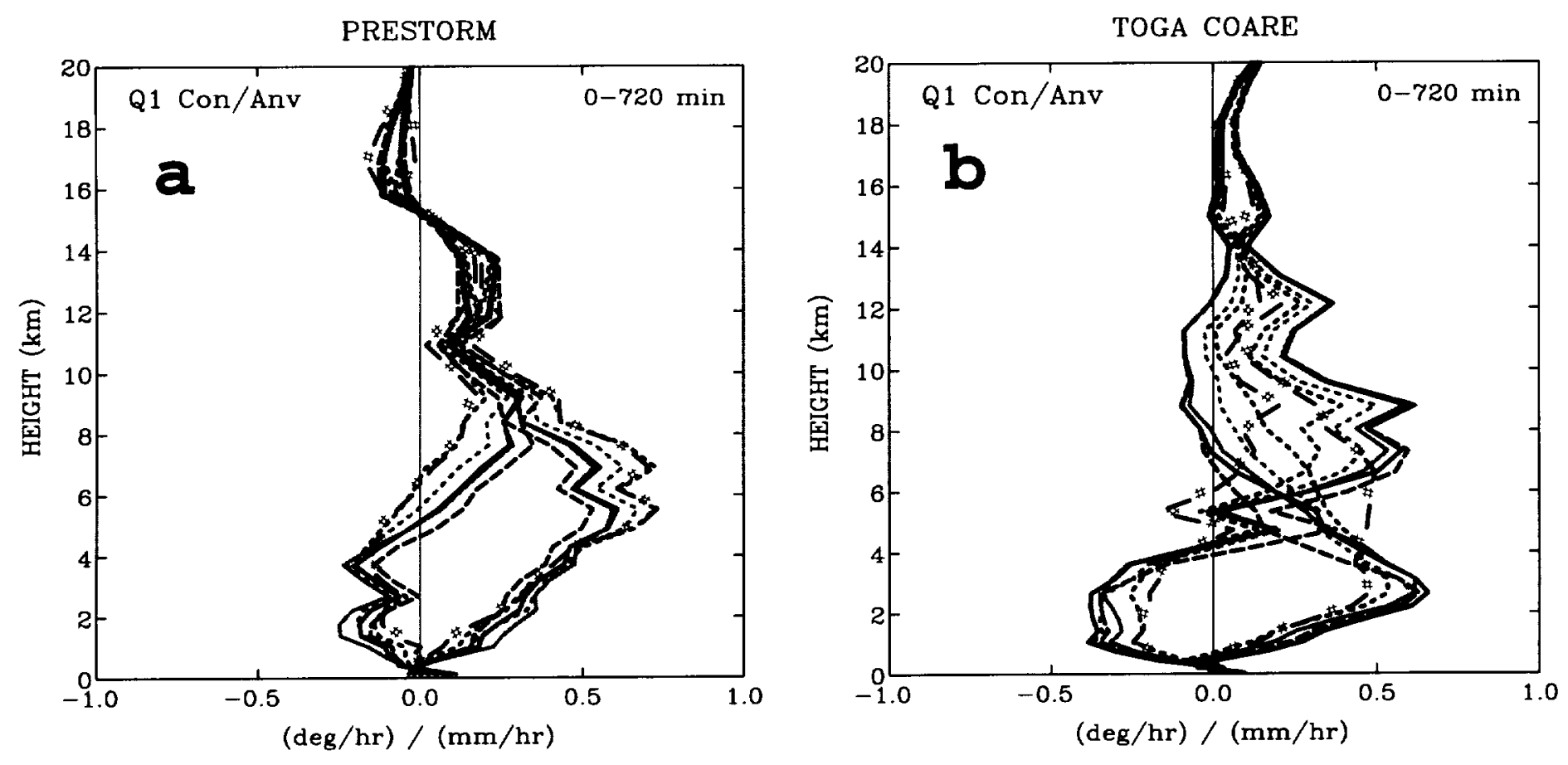

Fig 9 

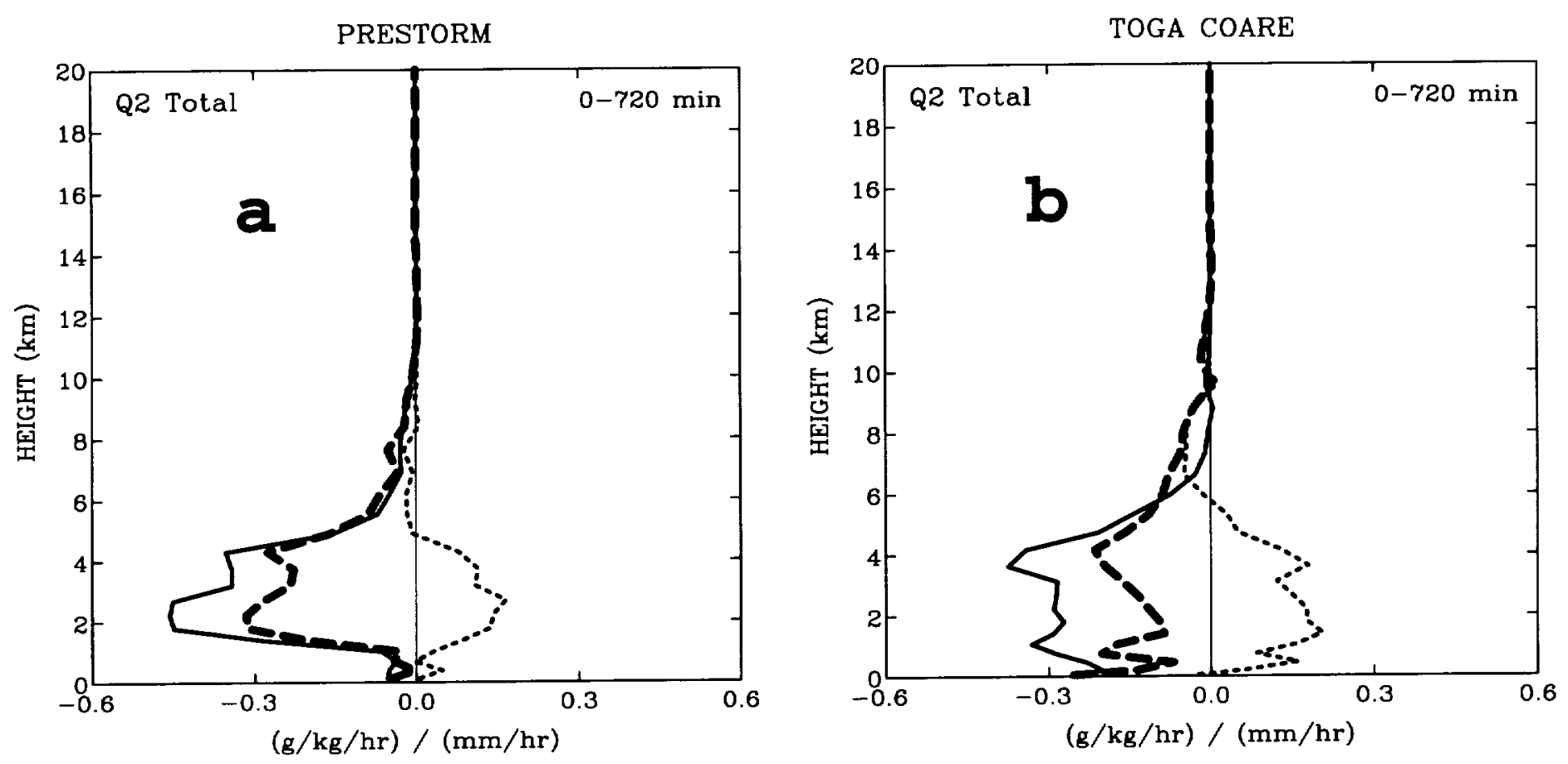

Fic 10 

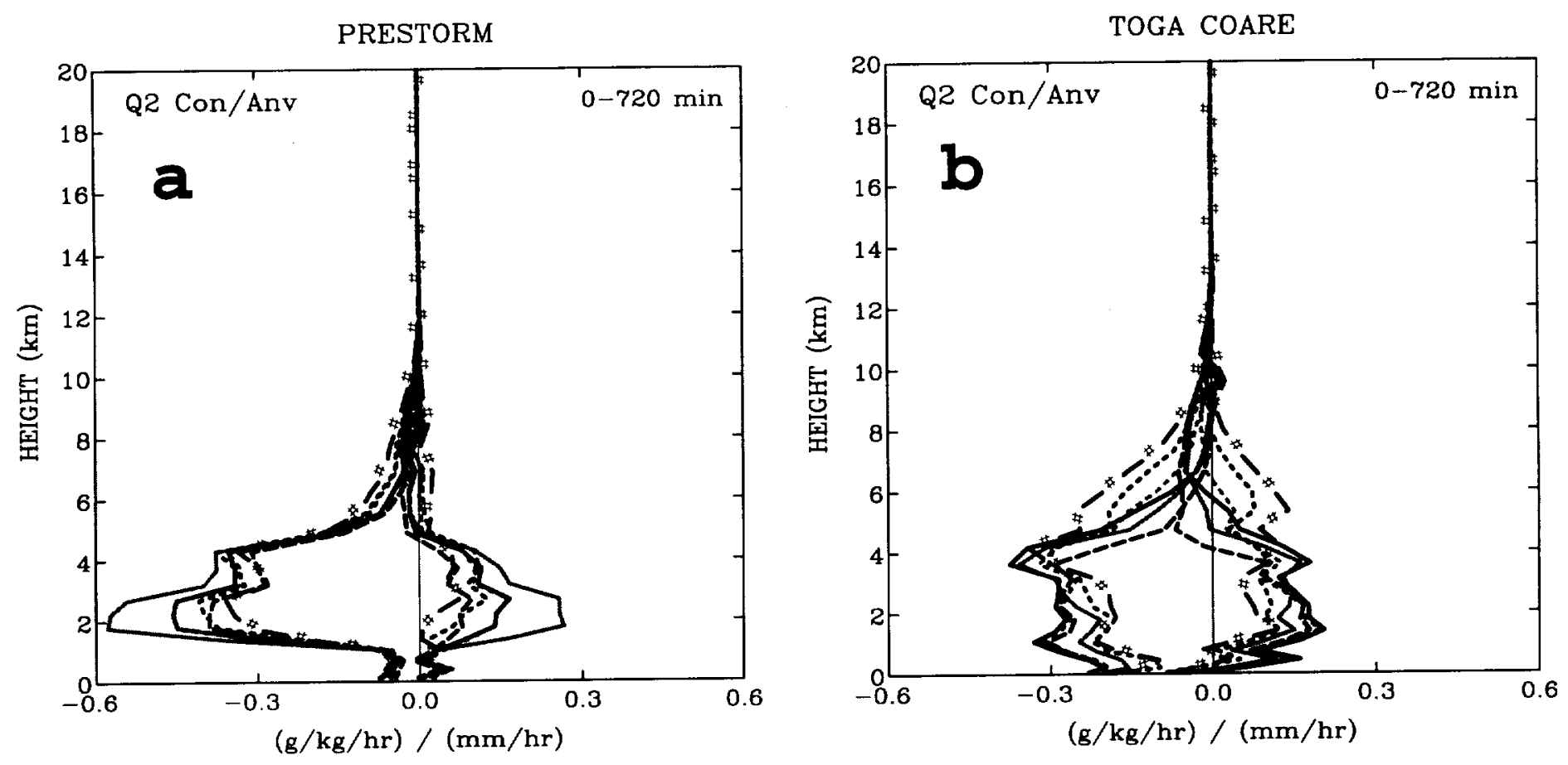

Fig 11 
PRESTORM

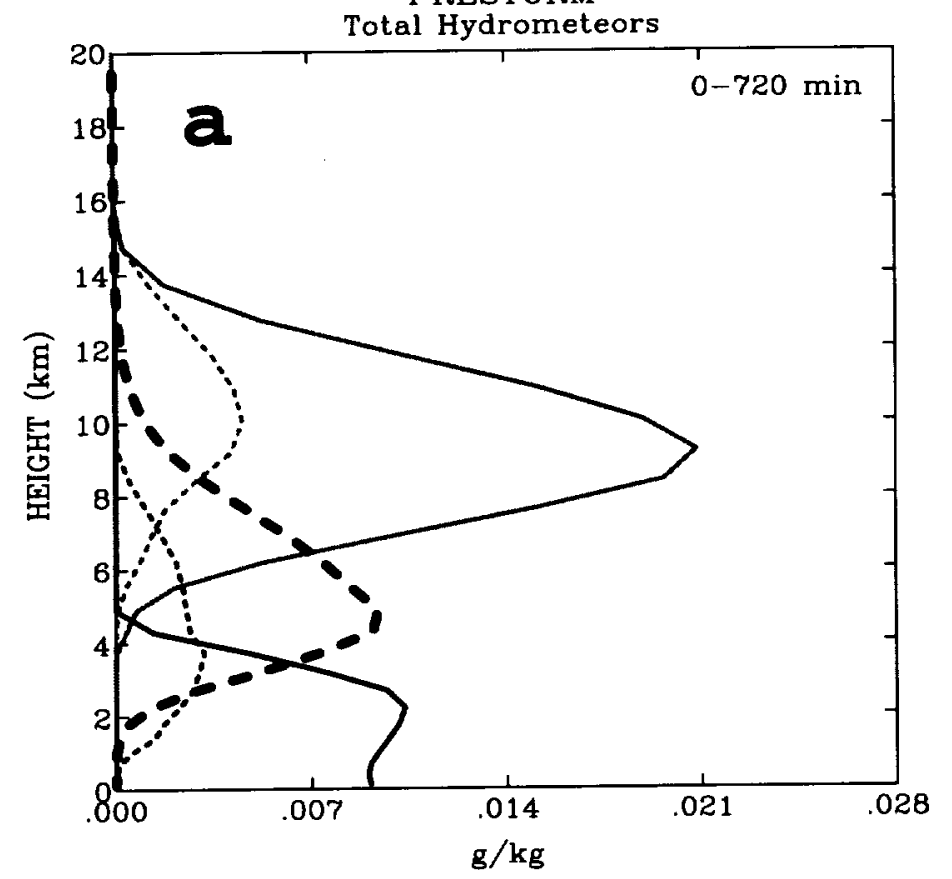

TOGA COARE

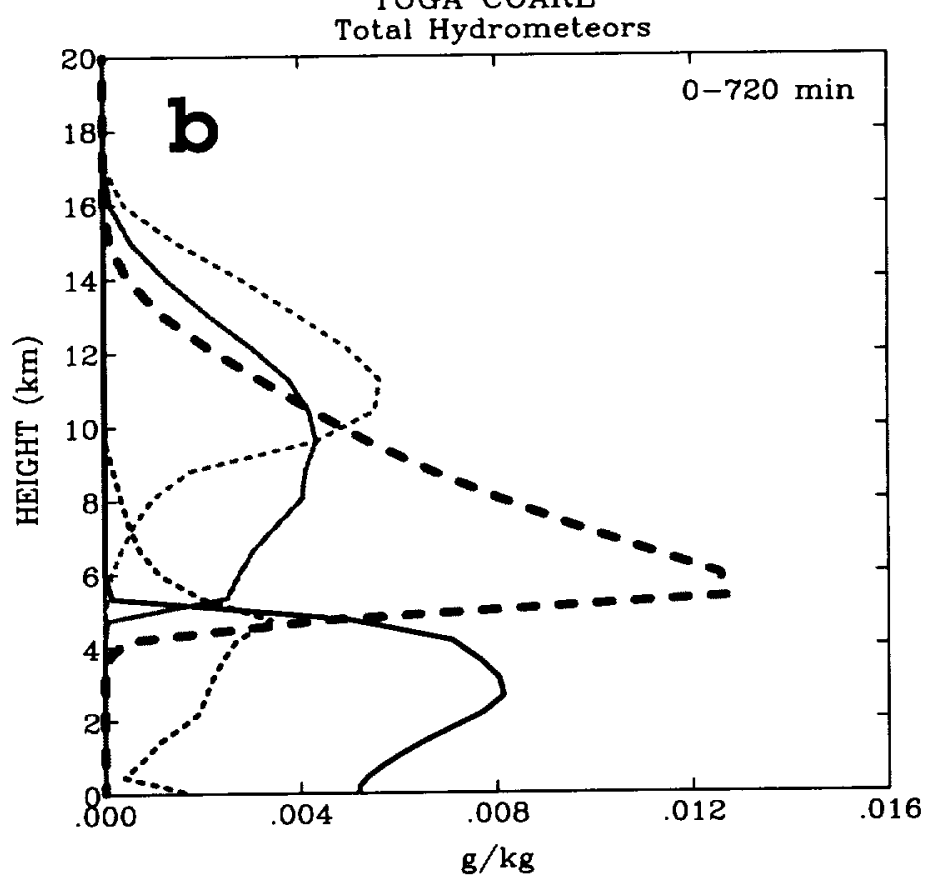



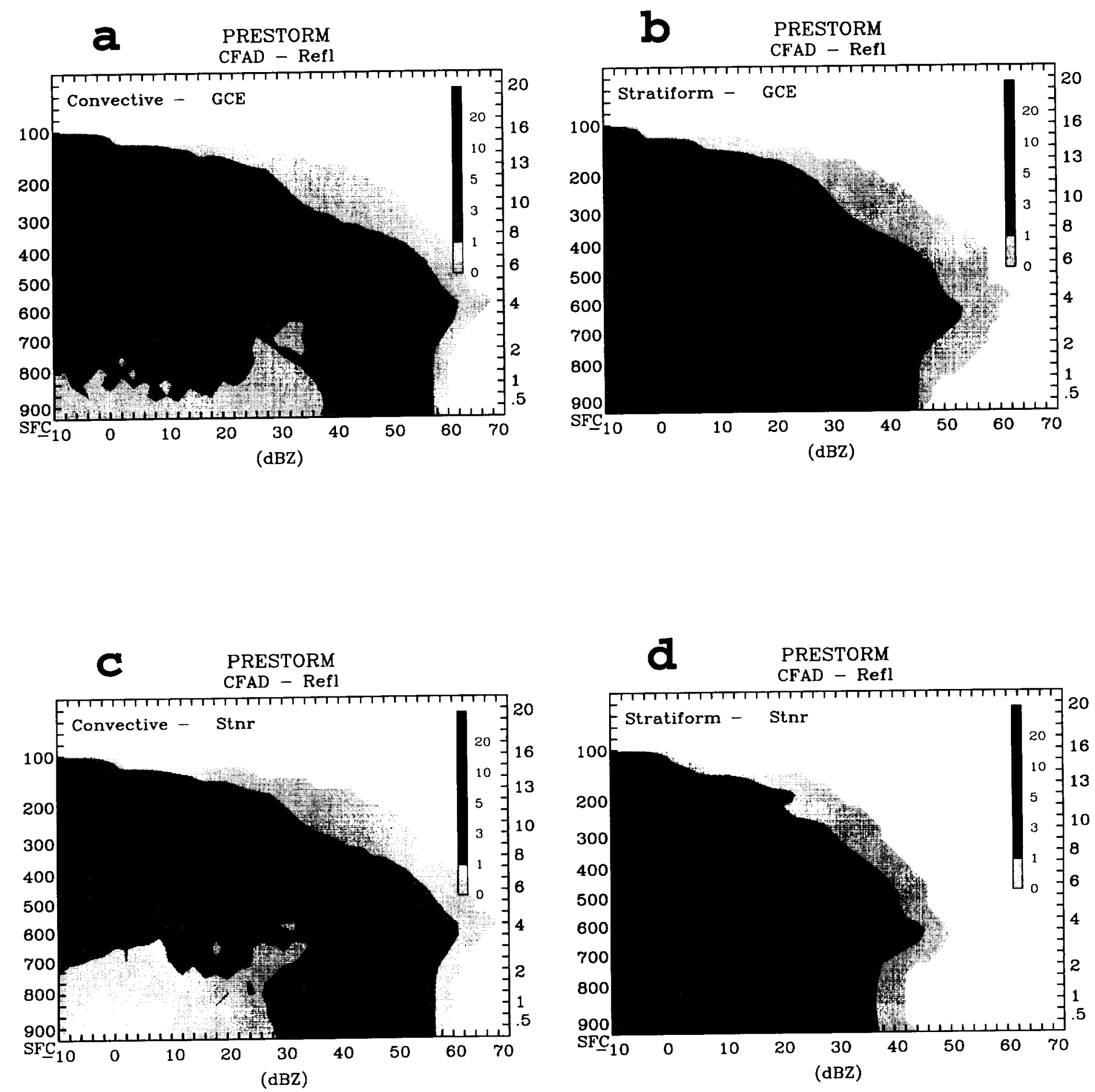

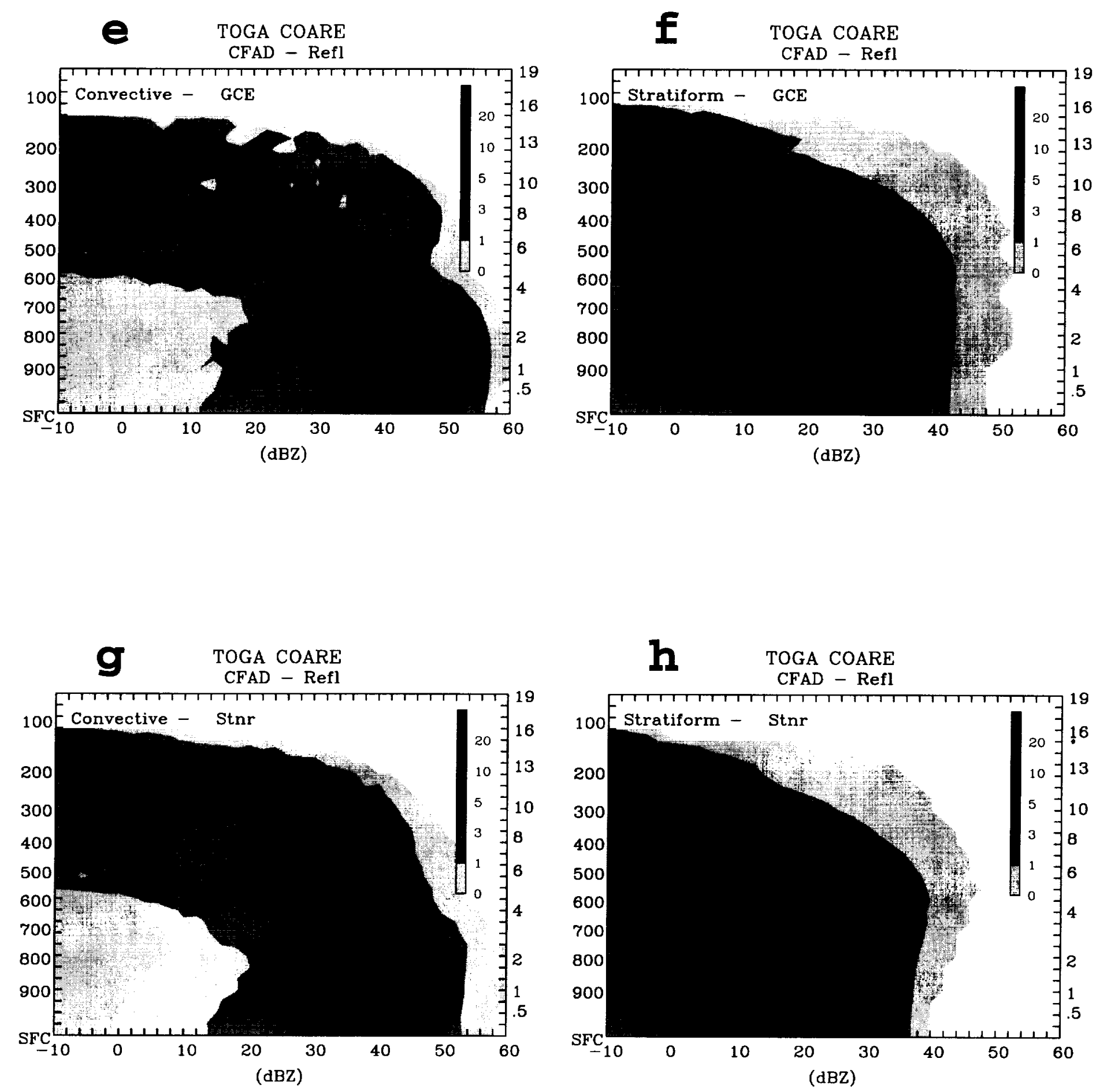

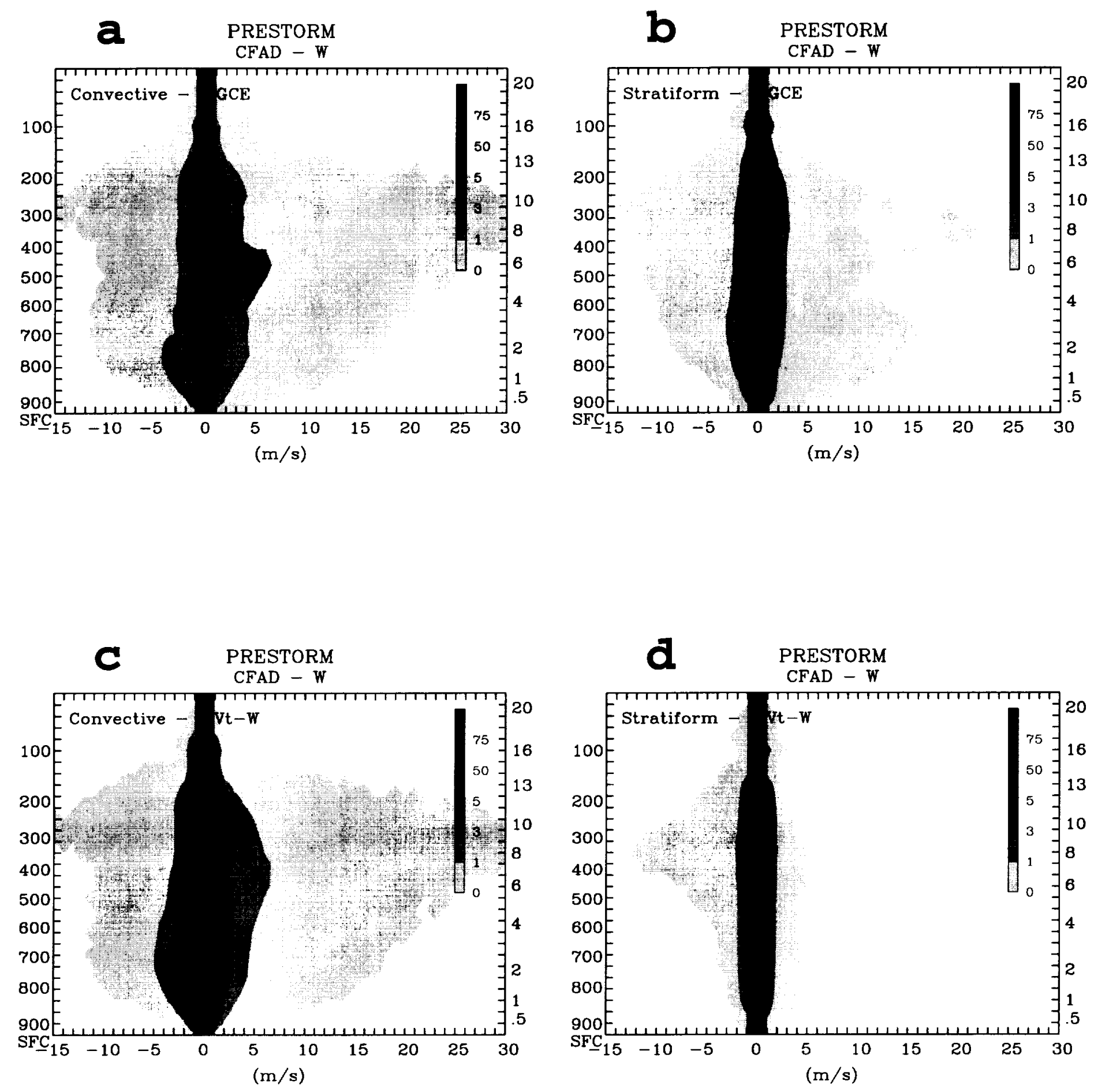

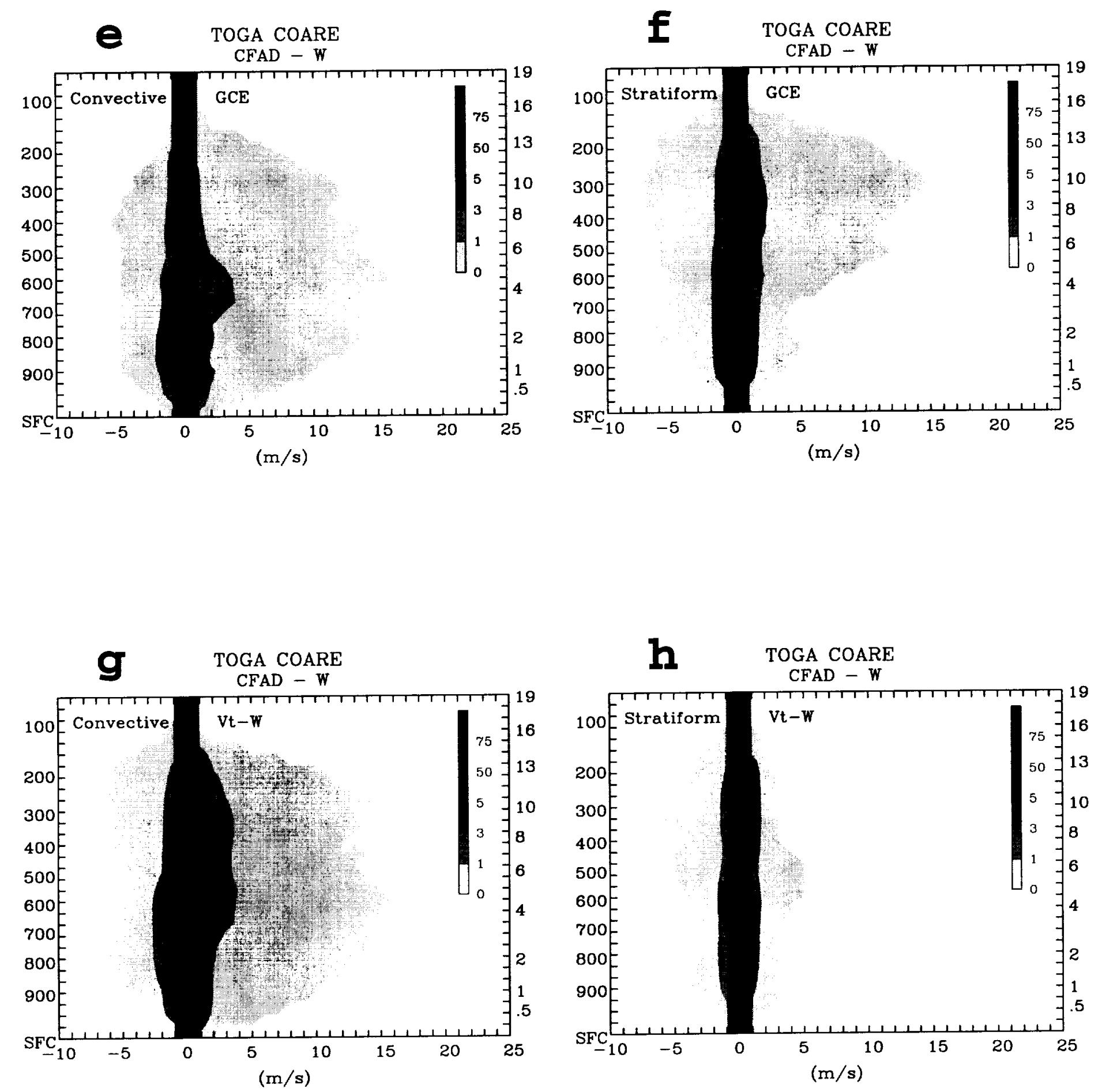

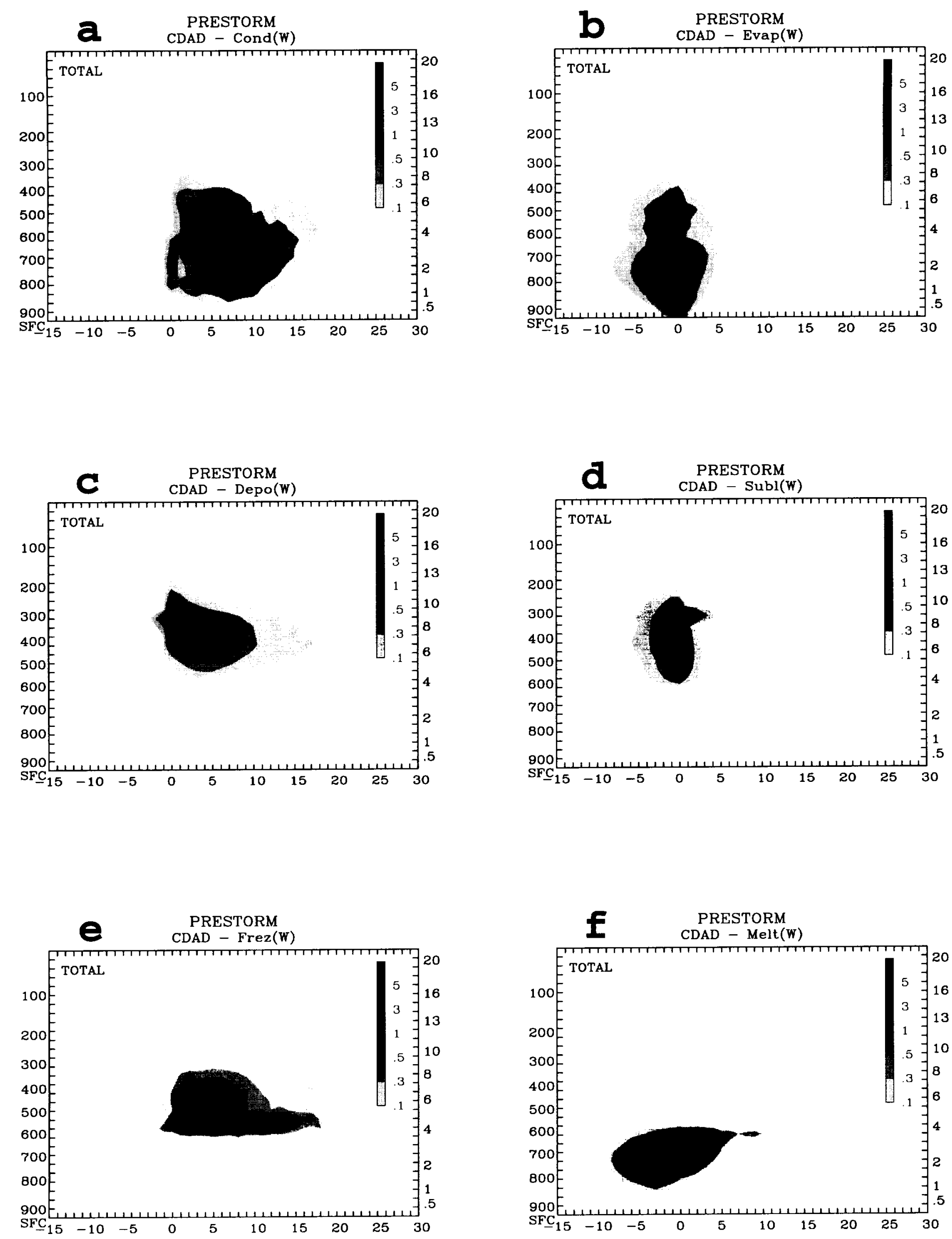

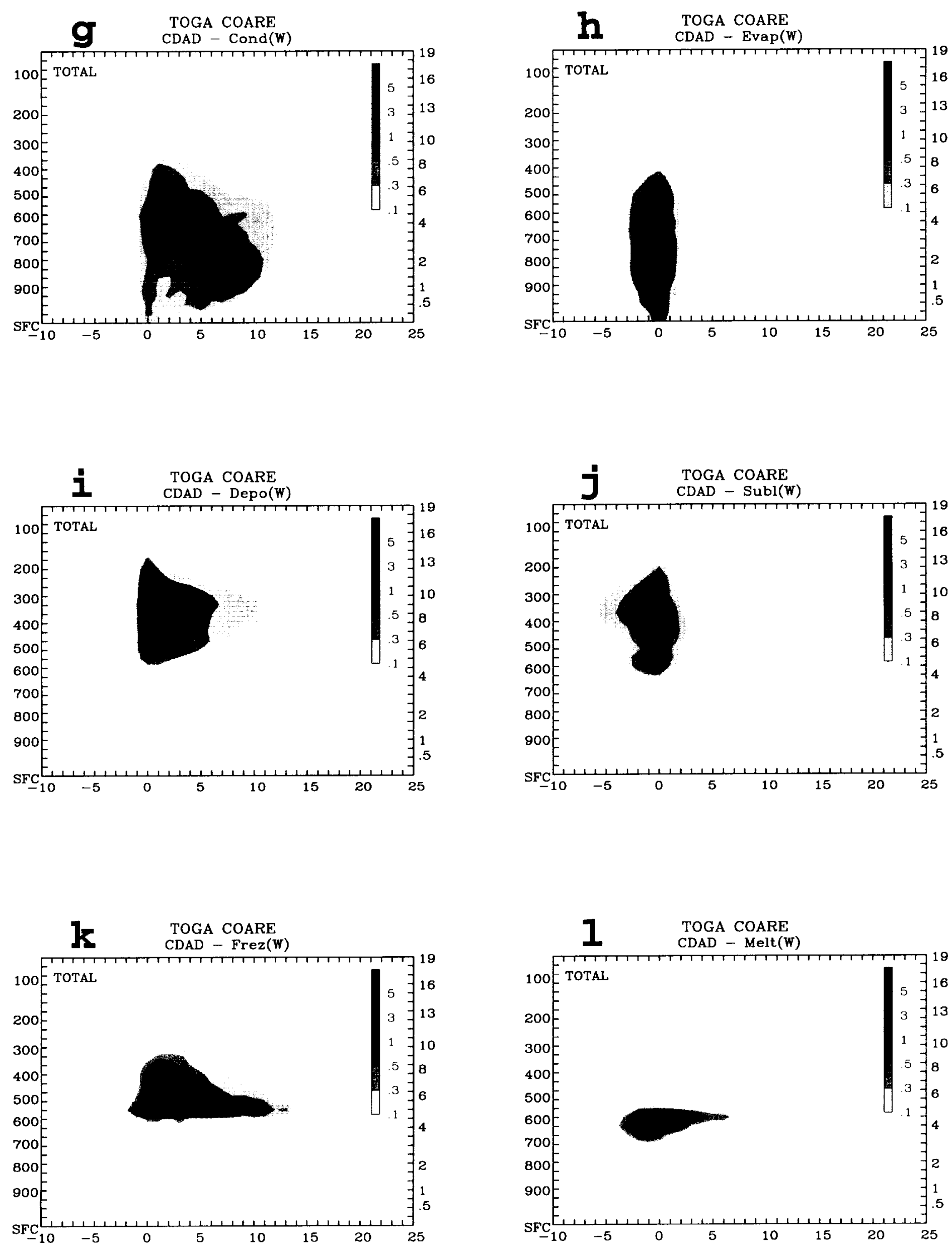

$F_{16} \quad 5\left(a_{n}\right)$ 

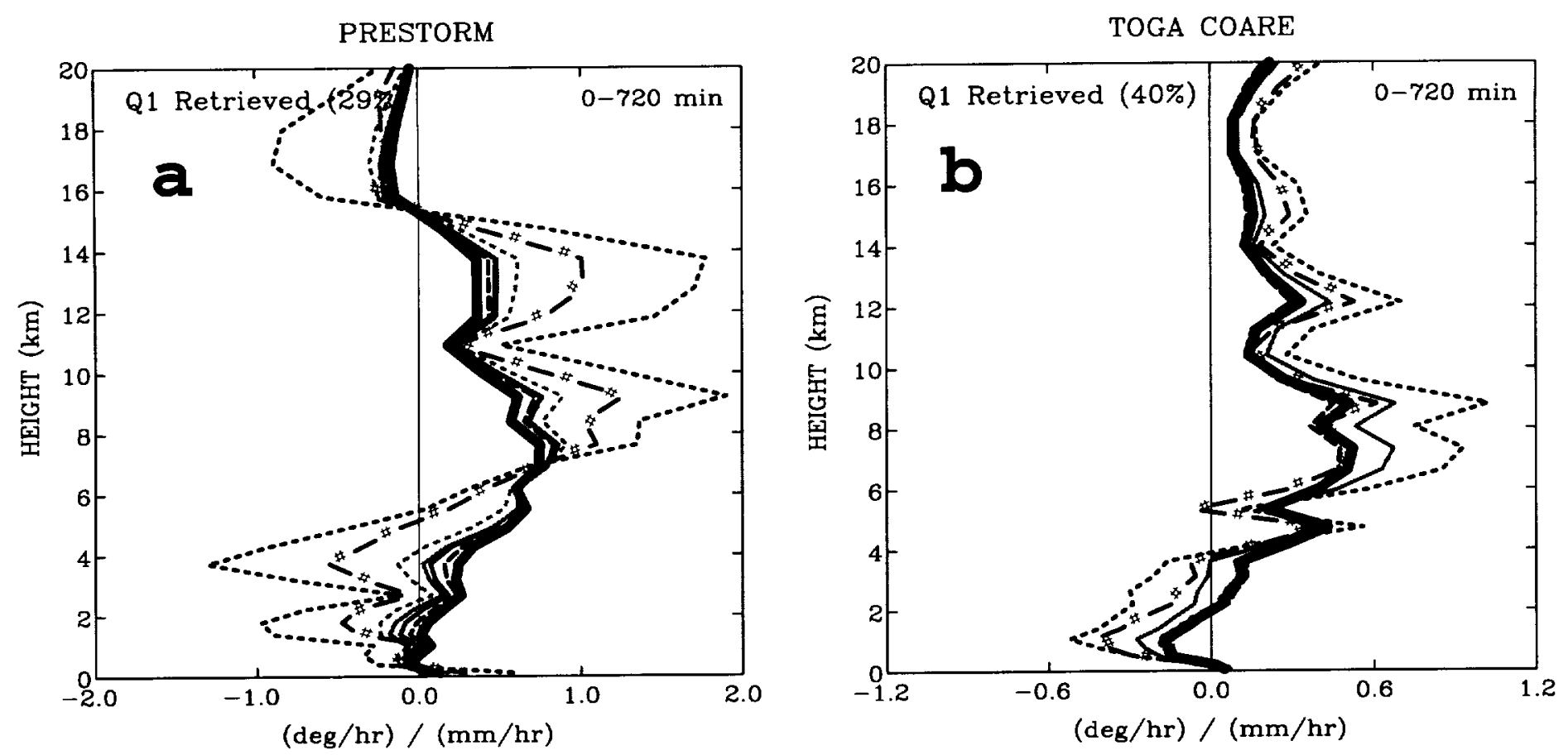

Fic: 16 
PRESTORM

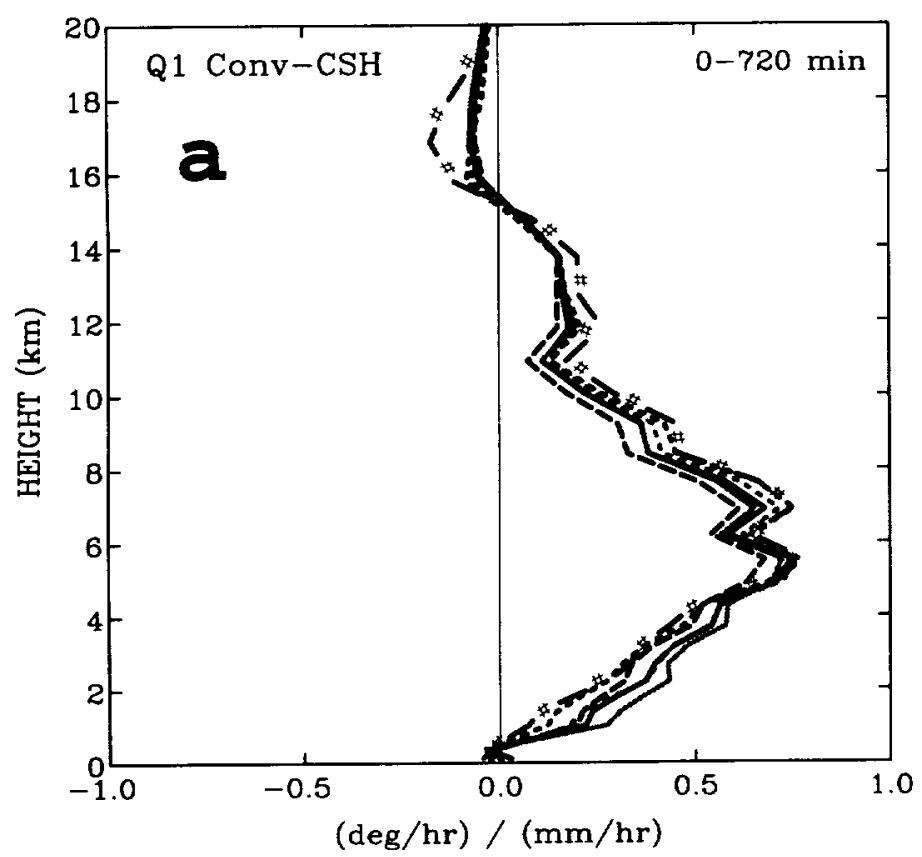

TOGA COARE

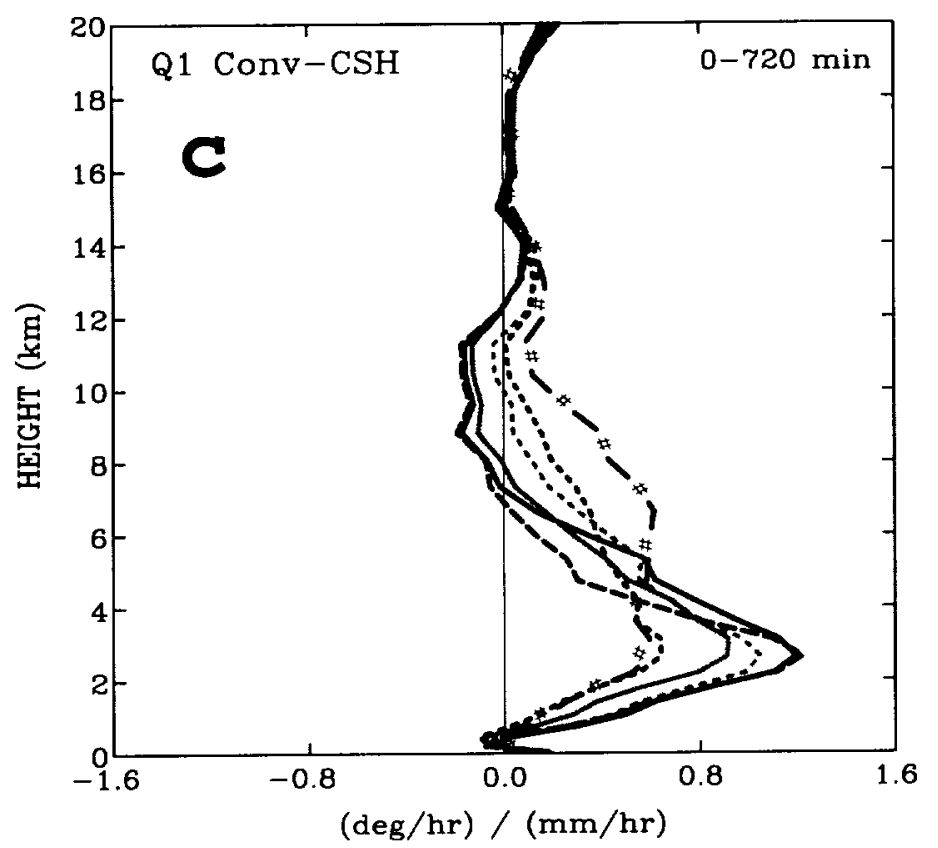

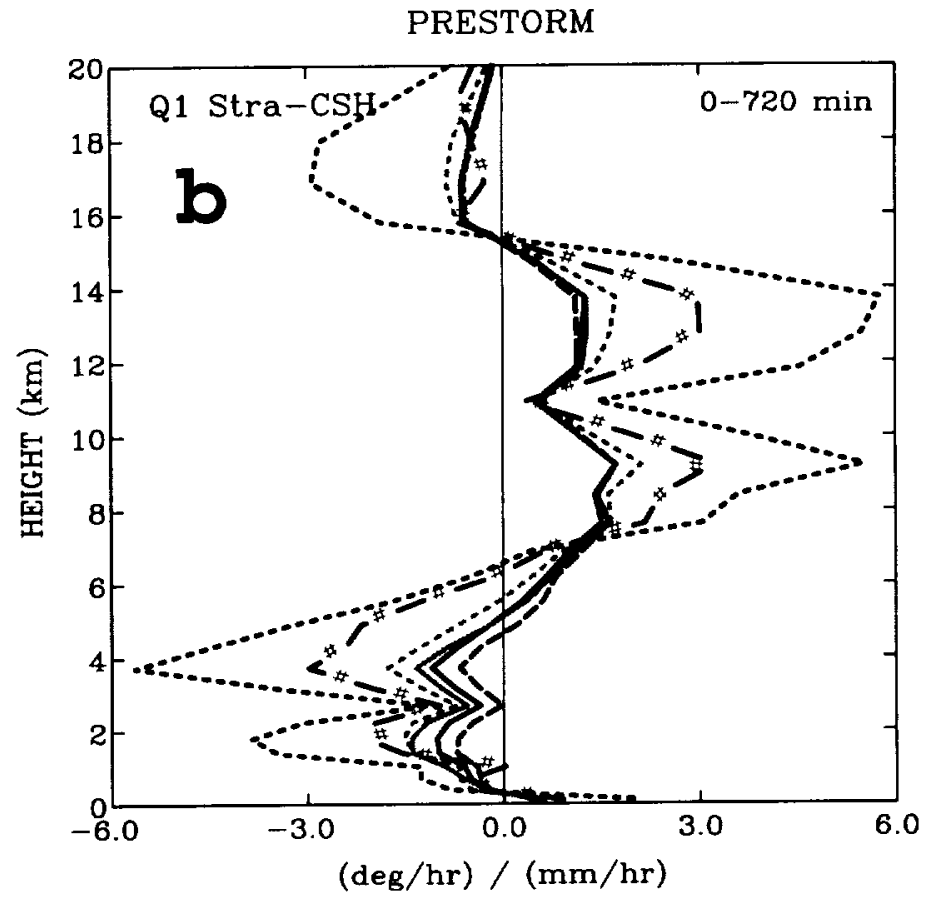

TOGA COARE

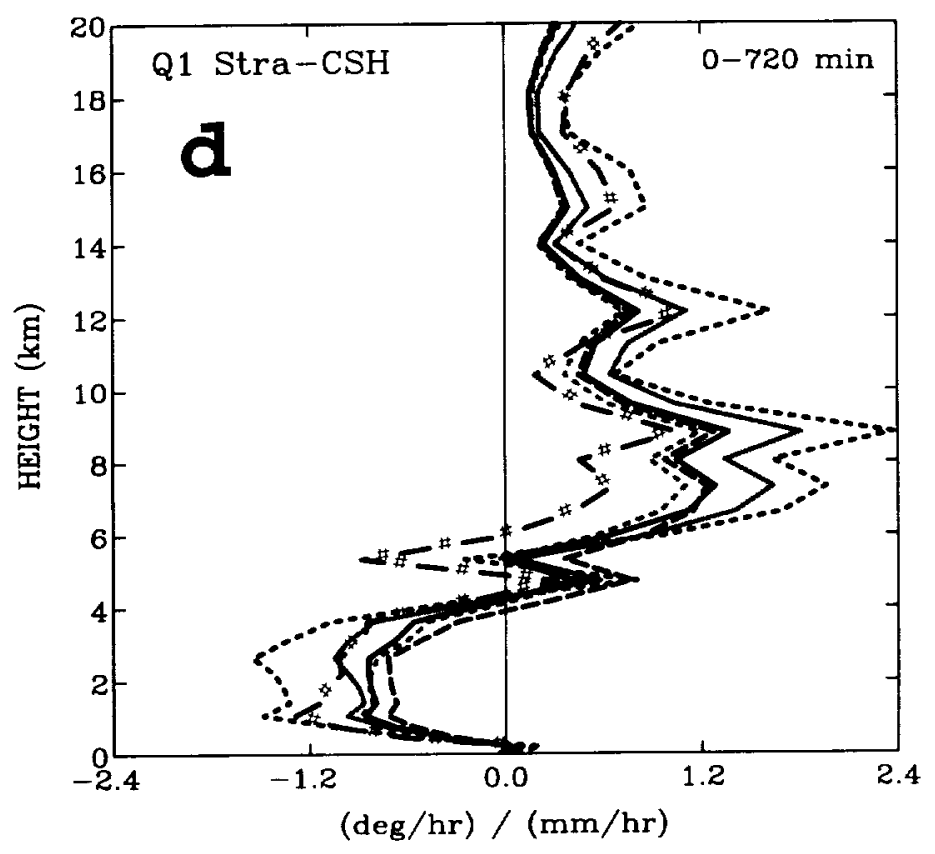

